\title{
A Spatial Gradient of Tau Protein Phosphorylation in Nascent Axons
}

\author{
James W. Mandell 1,2 and Gary A. Banker ${ }^{1}$ \\ Departments of ${ }^{1}$ Neuroscience and ${ }^{2} P a t h o l o g y$, Division of Neuropathology, University of Virginia School of Medicine, \\ Charlottesville, Virginia 22908
}

\begin{abstract}
Mechanisms underlying axonogenesis remain obscure. Although a large number of proteins eventually become polarized to the axonal domain, in no case does protein compartmentalization occur before or simultaneous with the earliest morphological expression of axonal properties. How then might initially unpolarized proteins, such as the microtubule-associated protein tau, play a role in the microdifferentiation of axons? We hypothesized that tau function could be locally regulated by phosphorylation during the period of axonogenesis. To test this hypothesis, we mapped relative levels of tau phosphorylation within developing cultured hippocampal neurons. This was accomplished using calibrated immunofluorescence ratio measurements employing phosphorylation state-dependent and state-independent antibodies. Tau in the nascent axon is more highly dephosphorylated at the site recognized by the tau- 1 antibody than tau in the somatodendritic compartment. The
\end{abstract}

change in phosphorylation state from soma to axon takes the form of a smooth proximo-distal gradient, with tau in the soma, immature dendrites and proximal axon $\sim 80 \%$ phosphorylated at the tau- 1 site, and that in the axonal growth cone only $20 \%$ phosphorylated. The existence of real spatial differences in tau phosphorylation state was confirmed by in situ phosphatase and kinase treatment. Pervanadate, a tyrosine phosphatase inhibitor, induced rapid tau dephosphorylation within live cells, effectively abolishing the phosphorylation gradient. Thus, the gradient is dynamic and potentially regulatable by upstream signals involving tyrosine phosphorylation. Phosphorylation gradients are likely to be present on many neuronal proteins in addition to tau, and their modulation by transmembrane signals could direct the establishment of polarity.

Key words: axonogenesis; polarity; tau; phosphorylation; gradient; microtubule
The generation of cellular asymmetry requires molecular mechanisms for local modification of intracellular structure. Although the establishment of neuronal polarity must involve the concerted activities of cytoplasmic, cytoskeletal, and membranous components (for review, see Craig and Banker, 1994), microtubules and microtubule-associated proteins (MAPs) are believed to play central roles in the microdifferentiation of axons and dendrites (Matus, 1988; Matus, 1990, 1991; Burgoyne, 1991; Cambray-Deakin, 1991; Gordon-Weeks, 1991; Hirokawa, 1991, 1994; Kosik and Caceres, 1991). Tau and MAP2, two major neuronal MAPs, are generally thought to be polarized to the axons and dendrites, respectively, of most mature neurons in vivo (Matus et al., 1981; Binder et al., 1985; Peng et al., 1986; Papasozomenos and Binder, 1987; Brion et al., 1988; Migheli et al., 1988; Trojanowski et al., 1989). Their differential distribution in maturity suggests a potential role in the initial development of neuronal polarity. Antisense experiments suggested an essential role for tau in axonogenesis (Caceres and Kosik, 1990; Caceres et al., 1991). The recent report of a tau-deficient transgenic mouse, however, in which there is no deleterious effect on axonogenesis suggests that tau is not necessary for axonal outgrowth in vivo (Harada et al., 1994). This discrepancy might be explained by upregulation of expression of

\footnotetext{
Received April 10, 1996; revised June 12, 1996; accepted June 27, 1996.

This work was supported by National Institutes of Health Grants NS09491 and NS17112. We thank Hannelore Asmussen for the preparation of neuronal cultures, and we thank the laboratories of Dr. Marc Kirschner and Dr. Sharon Greenberg and Immunogenetics for generous gifts of antibodies.

Correspondence should be addressed to Dr. James Mandell, Department of Pathology, Division of Neuropathology, P.O. Box 214, University of Virginia School of Medicine, Charlottesville, VA 22908.

Copyright (C) 1996 Society for Neuroscience $0270-6474 / 96 / 165727-14 \$ 05.00 / 0$
}

other functionally redundant MAPs (such as MAP1B) in the transgenic animal (Shastry, 1994).

If, indeed, MAPs are directly involved in the establishment of neuronal polarity, it seems likely that their distribution should become polarized before or in parallel with the acquisition of structural polarity. However, at least in vitro, both MAP2 and tau are uniformly distributed before and during early stages of axonogenesis (Caceres et al., 1986; Dotti et al., 1987; Ferreira et al., 1987; Kosik and Finch, 1987). How, then, might uniformly distributed MAPs have local (subcellular) influence on neuritic differentiation?

An attractive mechanism is locally controlled post-translational modification of MAPs. Phosphorylation is the major posttranslational modification of MAPs, and it is known to modulate the binding of both tau and MAP2 to microtubules (Lindwall and Cole, 1984; Yamamoto et al., 1988; Brugg and Matus, 1991; Drechsel et al., 1992; Gustke et al., 1992; Biernat et al., 1993; Garcia et al., 1993; Scott et al., 1993a,b). The discovery that the paired helical filaments (PHF) in neurofibrillary tangles of $\mathrm{Alz}$ heimer's disease are composed of abnormally hyperphosphorylated tau has fueled basic research on tau phosphorylation (Grundke-Iqbal et al., 1986; Wood et al., 1986; Kosik et al., 1988; Steiner et al., 1990; Lee et al., 1991; Hasegawa et al., 1992). Roles for tau phosphorylation in normal neurons, during both development and maturity, however, remain elusive.

To determine whether spatial differences in tau protein phosphorylation exist within cellular compartments of developing neurons, we have used a semiquantitative immunofluorescence ratio analysis method to measure phosphorylation within processes of cultured hippocampal neurons. Our results demonstrate the pres- 
Table 1. Characteristics of anti-tau antibodies utilized

\begin{tabular}{lllll} 
& Type $^{a}$ & Dilution $^{b}$ & Phosphorylation dependence & Source \\
\hline Tau-1 & Mono & $5,0.25 \mu \mathrm{g} / \mathrm{ml}$ & Dephospho-(Ser-199/202) & Boehringer Mannheim \\
BT2 & Mono & $10 \mu \mathrm{g} / \mathrm{ml}$ & Dephospho-(Ser-199/202) & Innogenetics \\
AT120 & Mono & $10 \mu \mathrm{g} / \mathrm{ml}$ & Phospho-independent & Innogenetics \\
PHF-1 & Mono & $1: 50,1: 500$ & Phospho-(Ser-396) & Dr. S. Greenberg (Cornell) \\
7A5 & Poly & $1: 400,1: 8000$ & Phospho-independent & A. Himmler (Genentech), provided \\
& & & & by Dr. J. Sabry (Harvard)
\end{tabular}

${ }^{a}$ Monoclonal (mono), polyclonal (poly).

${ }^{b}$ Dilution used for immunofluorescence, immunoblotting.

ence within nascent axons of a proximo-distal gradient of phosphorylation. Furthermore, perturbation of the gradient by pervanadate suggests that it is dynamically regulated in living cells under the potential influence of upstream signals involving tyrosine phosphorylation.

\section{MATERIALS AND METHODS}

Antibodies. The anti-tau antibodies used are characterized in Table 1. Preliminary serial dilution experiments were performed to determine qualitatively the minimal antibody concentrations sufficient for nonsaturating, specific immunofluorescence labeling. The monoclonal antiphosphotyrosine antibody 4G10 was obtained from UBI (Lake Placid, $\mathrm{NY}$ ) and used at a dilution of $5 \mu \mathrm{g} / \mathrm{ml}$ for immunofluorescence and 0.5 $\mu \mathrm{g} / \mathrm{ml}$ for immunoblotting. Affinity-purified goat anti-mouse fluorescein isothiocyanate and goat anti-rabbit tetramethyl rhodamine isothiocyanate secondary antibodies (Boerhinger Mannheim, Indianapolis, IN) were used at a dilution of 1:200 as described below. These were shown not to cross-react with rabbit or mouse primary antibodies, respectively, in control experiments. For immunoblotting, alkaline phosphatase-conjugated goat anti-mouse or goat anti-rabbit IgG was used at a dilution of 1:7500 as recommended by the manufacturer (Promega, Madison, WI).

Cell culture. Hippocampal cultures were prepared as described previously (Goslin and Banker, 1991). Hippocampi from $18 \mathrm{~d}$ fetal rats were treated with trypsin $\left(0.25 \%\right.$ for $15 \mathrm{~min}$ at $\left.37^{\circ} \mathrm{C}\right)$ and dissociated by trituration with a Pasteur pipette. Cells were plated on poly-L-lysinetreated glass coverslips (Fisher Scientific, catalog \#18-CIR-1D) in minimal essential medium (MEM) with $10 \%$ horse serum at a density of 1500-2500 cells $/ \mathrm{cm}^{2}$. After allowing 2-3 $\mathrm{hr}$ for cell attachment, the coverslips were transferred to dishes containing a confluent glial monolayer in serum-free MEM with N2 supplements, $0.1 \%$ ovalbumin, and 0.1 nM pyruvate. For some immunoblotting experiments, cells were plated in poly-L-lysine-treated $35 \mathrm{~mm}$ tissue culture dishes at a density of 20,000$40,000 \mathrm{cells} / \mathrm{cm}^{2}$ and maintained in glial-conditioned medium.

SDS-PAGE and Western blot analysis. Dishes $(35 \mathrm{~mm})$ or glass coverslips were drained of medium and rinsed in HBSS, and the neurons were dissolved by scraping in $2 \times$ Laemmli sample buffer (Laemmli, 1970). The samples were heated to $90^{\circ} \mathrm{C}$ for $5 \mathrm{~min}$ and centrifuged for $5 \mathrm{~min}$ at maximum speed on a microfuge and either used immediately for electrophoresis or stored at $-20^{\circ} \mathrm{C}$. Samples were electrophoresed in $7.5 \%$ SDS-polyacrylamide gels and electrophoretically transferred to nitrocellulose or PVDF (Towbin et al., 1979). Before application of antibody, blots were incubated for $12-18 \mathrm{hr}$ at $4^{\circ} \mathrm{C}$ in blocking buffer (PBS, 5\% nonfat dry milk, $1 \%$ BSA, $0.05 \%$ Tween-20).

Alkaline phosphatase treatment of blots was performed for $3 \mathrm{hr}$ at $37^{\circ} \mathrm{C}$ $(130 \mathrm{U} / \mathrm{ml}$ Sigma calf intestinal alkaline phosphatase in $100 \mathrm{~mm}$ Tris buffer, $\mathrm{pH} 8.5,1 \mathrm{~mm}$ PMSF, $20 \mu \mathrm{g} / \mathrm{ml}$ pepstatin A, $20 \mu \mathrm{g} / \mathrm{ml}$ leupeptin). Control blots were treated identically except for the omission of enzyme from the buffer.

Incubation in primary antibody (diluted in blocking buffer) was carried out in a rotating drum apparatus for $2 \mathrm{hr}$ at room temperature. After thorough washing in blocking buffer (omitting BSA), blots were incubated for $1 \mathrm{hr}$ at room temperature with secondary alkaline phosphataseconjugated antibodies in blocking buffer. Immunolabeled bands were visualized by the addition of the alkaline phosphatase substrate BCIP/ NBT (Pierce, Rockford, IL).

In situ phosphorylation and dephosphorylation. The in situ phosphorylation method is a modification of a previously published biochemical protocol (Goedert et al., 1993). A brain kinase extract was prepared by homogenizing total adult rat forebrain $(1 \mathrm{gm} / 2.5 \mathrm{ml})$ in $10 \mathrm{~mm}$ Tris $\mathrm{HCl}$, $\mathrm{pH} 7.4,5 \mathrm{~mm}$ EGTA, $2 \mathrm{~mm}$ dithiothreitol, $1 \mu \mathrm{M}$ okadaic acid, $1 \mathrm{~mm}$ PMSF, $20 \mu \mathrm{g} / \mathrm{ml}$ leupeptin, and $20 \mu \mathrm{g} / \mathrm{ml}$ pepstatin. The homogenate was centrifuged at $50,000 \times g$ for $1 \mathrm{hr}$ at $4^{\circ} \mathrm{C}$. The resultant supernatant was used immediately or stored at $-70^{\circ} \mathrm{C}$. Cells fixed for $30 \mathrm{~min}$ in $4 \%$ formaldehyde were rinsed in PBS and blocked for $2 \mathrm{hr}$ in blocking buffer (PBS, $10 \%$ NGS, $0.2 \%$ Triton X-100). After a final rinse in $40 \mathrm{~mm}$ HEPES ( $\mathrm{pH} 7.2), 100 \mu \mathrm{l}$ of the kinase extract diluted 1:10 (v/v) in phosphorylation buffer (40 mM HEPES, pH 7.2, 2 mM ATP, 2 mM $\mathrm{MgCl}_{2}$, 5 mM EGTA, 2 mM dithiothreitol, $1 \mu \mathrm{M}$ okadaic acid, 1 mM PMSF, 20 $\mu \mathrm{g} / \mathrm{ml}$ leupeptin, $20 \mu \mathrm{g} / \mathrm{ml}$ pepstatin) was added to each coverslip. In control experiments, the kinase extract and/or ATP was omitted from the solution. Coverslips were incubated at $37^{\circ} \mathrm{C}$ for $18 \mathrm{hr}$ with continuous agitation in a humidified chamber. After washing with PBS, coverslips were processed for immunofluorescence as described below. Dephosphorylation was accomplished by alkaline phosphatase treatment of fixed cells, as described above for immunoblots, except that $36 \mathrm{U} / \mathrm{ml}$ Escherichia coli alkaline phosphatase (Sigma, St. Louis, MO) was used at $67^{\circ} \mathrm{C}$ for $2 \mathrm{hr}$ (Goedert et al., 1992). Preliminary experiments using calf intestinal phosphatase at $37^{\circ} \mathrm{C}$ demonstrated a qualitatively similar effect, but quantitative analysis revealed that dephosphorylation was more complete with the bacterial enzyme.

Immunofluorescence microscopy. Cells were fixed in $4 \%$ formaldehyde in PBS/sucrose prewarmed to $37^{\circ} \mathrm{C}$ for $30-45 \mathrm{~min}$, permeabilized in $0.3 \%$ Triton X-100 for $5 \mathrm{~min}$, and rinsed several times in PBS. Fixation time was found to be a critical factor for the demonstration of polarized tau-1 immunostaining; cells fixed for less than 10 min exhibited tau-1 labeling in all cell compartments, possibly because of continued phosphatase activity in the lightly fixed cells (see Fig. $2 C-F$ ). [A previous report from this laboratory (Dotti et al., 1987) concluded that immunostaining with the tau-1 antibody was present in all processes, although slightly more prominent in the axon. This discrepancy-along with reports from other laboratories of inconsistent results with tau-1 immunostaining of cultured neurons (Diaz et al., 1992) — can likely be attributed to the sensitivity of this epitope to differences in fixation as well as phosphorylation state (see also Mandell and Banker, 1995).]

To extract unassembled tubulin before fixation, cells were rinsed briefly in HBSS and extracted for $2 \mathrm{~min}$ at room temperature in a detergentcontaining, microtubule-stabilizing buffer (20 mM PIPES, pH 6.9, 2 mM EGTA, $2 \mathrm{mM} \mathrm{MgCl}_{2}, 1 \mathrm{~mm}$ PMSF, $0.5 \%$ Triton X-100). They were then fixed by immersion in methanol at $-20^{\circ} \mathrm{C}$ for $5 \mathrm{~min}$, allowed to air dry, and rehydrated in PBS.

All antibody incubations and washes were performed at room temperature as follows: (1) $1 \mathrm{hr}$ block in PBS/2.5\% BSA; (2) $2 \mathrm{hr}$ incubation in primary antibody diluted in $\mathrm{PBS} / 2.5 \% \mathrm{BSA}$; (3) three 10 min rinses in wash buffer ( $450 \mathrm{~mm} \mathrm{NaCl}, 0.3 \%$ Triton X-100, 20 mm sodium phosphate buffer, $\mathrm{pH}$ 7.4) and one in PBS (30 min); (4) $1 \mathrm{hr}$ incubation in secondary antibody diluted in PBS/2.5\% BSA; and (5) three 10 min rinses in wash buffer and one in PBS (30 min) for $30 \mathrm{~min}$. After a final rinse in distilled water, coverslips were mounted on glass slides in a polyvinyl alcoholbased mountant containing $2 \%$ diazobicyclooctane. Where indicated, photomicrographs were acquired using identical exposures and printing conditions to allow meaningful comparison between micrographs of immunofluorescence brightness. Illustrations of digital images were prepared by directly photographing the computer screen or with a Polaroid Digital Palette.

Image acquisition and ratio measurements. Epifluorescence was imaged with Zeiss fluorescence filter sets for rhodamine (model 4877-15; exciter, $546 \mathrm{~nm}$; dichroic beam splitter, $580 \mathrm{~nm}$; barrier filter, 590) and fluorescein 
(model 4877-10; exciter, 450-490 nm; dichroic beam splitter, $510 \mathrm{~nm}$; barrier filter, 515-565 nm). These independent filter sets allow negligible $(<1 \%)$ crossover between rhodamine and fluorescein signals. Images were captured using a Hamamatsu SIT camera (model 2400), a Uniblitz shutter, and Image-1 software (Universal Imaging, Chester, PA). The camera and frame grabber were used at fixed gain settings previously determined to give a linear response. Initial tests for linearity in the imaging system were performed using a series of optical density filters and a saturating fluorescent test object. An additional assurance of linearity was performed on each data image acquired: a threedimensional intensity contour plot created by the Image- 1 software was examined for evidence of saturation (which appeared as a plateau in the intensity profile).

Ratio plots were constructed as follows: using the line intensity scan function of Image-1, with averaging across a 3 pixel width, multiple intensity scans were acquired perpendicular to the longitudinal axis of the neurite going from axon origin to growth cone. Intensity scans for the tau-1 (fluorescein) and 7A5 (rhodamine) images were taken at identical positions along the axon. Each intensity scan thus represents a profile of fluorescence intensity across the neurite, including adjacent background fluorescence. The pixel intensity values for each scan as well as the calibrated $x, y$ coordinates of the pixels sampled were stored as a text file. A custom BASIC program automatically calculated for each pair of scans the $x, y$ position of the peak intensity value, the calibrated running distance along the neurite, the background intensity level (averaged from the first and last 5 pixels in the scan), the integrated pixel intensity (the sum of the background-subtracted intensities within the scan), and the fluorescence ratio (tau-1 fluorescein/7A5 rhodamine). Fluorescence intensities, representing the integrated brightness across the scan in arbitrary digital units (ADUs) and the ratio of tau- 1 fluorescein to 7A5 rhodamine fluorescence, were plotted against distance along the neurite, measured from the soma to the tip of the growth cone. Our ratio immunofluorescence measurement method is similar in principle to one previously described by Black and colleagues (Brown et al., 1992), which used a segmented mask rather than a series of line scans to acquire data points.

To test for possible nonlinearity in the ratio measurements, the procedure was applied to a pair of cell images, identical to each other except that one was reduced in intensity to $32 \%$ with a neutral density filter. The resultant ratio measurements, plotted along the length of the axon, closely fit a flat line with a ratio value close to the percent transmission of the neutral density filter. The ratio obtained was unaffected by the wide range of absolute intensities along the axon, indicating the robustness of the ratio measurement procedure. Moreover, measurements on cells double-labeled with two phosphorylation-independent antibodies (7A5 and AT120) gave flat axonal ratio profiles.

Some images were obtained using a Photometrics AT200-cooled charge-coupled device (CCD) camera in conjunction with the MetaMorph image analysis system (Universal Imaging). A pair of backgroundsubtracted 16 bit images (tau-1-fluorescein and 7A5-rhodamine) was acquired with the cooled CCD camera. The digital images were manually aligned so as to correct for image shift introduced by the fluorescence filters. Integrated intensities were measured within a $36 \mu \mathrm{m}^{2}$ region at proximal, middle, or distal portions of neurites and fluorescence ratios calculated directly from these measurements.

\section{RESULTS}

\section{Phosphorylation state dependence of anti-tau antibodies: characterization of tau in cultured hippocampal neurons by immunoblotting}

Our method for measurement of relative levels of tau phosphorylation within cultured neurons required a pair of tau antibodies with the following properties. (1) Of the pair, one should recognize tau protein independent of phosphorylation state and the other should specifically recognize a phosphorylated or dephosphorylated tau epitope. (2) The epitopes recognized by the two antibodies should be spatially separate on the tau molecule so that the binding of one antibody does not interfere with binding of the other. (3) Both antibodies should recognize epitopes common to all differentially spliced tau isoforms so that the ratio measurements are not complicated by differences in isoform expression. (4) The two antibodies should be derived from different species to enable double-labeling. To satisfy these criteria, we chose a polyclonal anti-peptide antibody, 7A5, and the monoclonal antibody tau-1. 7A5 was raised against a peptide representing the N-terminal 33 amino acids of bovine tau (Himmler et al., 1989). Tau-1 was raised against bovine tau, it but cross-reacts with adult rat tau protein (Binder et al., 1985). This well characterized antibody is thought to require dephosphorylation at four nearby serine residues $\left(\operatorname{Ser}^{195}, \operatorname{Ser}^{198}, \operatorname{Ser}^{199}\right.$, and $\mathrm{Ser}^{202}$; numbered as in the longest human tau isoform) for high-affinity binding (Szendrei et al., 1993).

We examined by immunoblotting the expression of tau after $1 \mathrm{~d}$ in culture, when the neurons begin to extend axons. For comparison, protein samples from embryonic day 18 (E18) and adult hippocampus (AD) were run in parallel. At $1 \mathrm{~d}$ in culture, total tau protein, as detected by antibody 7A5, was present as two closely spaced bands around $50 \mathrm{kDa}$, identical to those in E18 hippocampus (Fig. 1, lanes 1, 2). Adult hippocampus contains higher molecular weight isoforms that arise from alternative mRNA splicing (lane 3) (Goedert et al., 1989, 1991; Kanai et al., 1989). In contrast to antibody 7A5, tau- 1 recognized a single band in $1 \mathrm{~d}$ cultures and E18 hippocampus that comigrated with the lower portion of the 7A5 band (lanes 4,5). Alkaline phosphatase treatment of the blot increased tau-1 immunoreactivity and revealed the slower migrating upper band in $1 \mathrm{~d}$ cultures and E18 hippocampus, consistent with the unmasking of tau-1 sites in a tau fraction that is normally highly phosphorylated (lanes 7,8). Alkaline phosphatase treatment had no effect on the banding pattern or intensity of 7A5 immunoreactivity, consistent with its phosphorylation state independence (data not shown).

\section{Simultaneous localization of total tau protein and the tau-1 epitope within developing hippocampal neurons: tau is uniformly distributed but preferentially dephosphorylated in the nascent axon}

The development of cellular polarity by neurons has been studied largely from the perspective of cell culture (for review, see Craig and Banker, 1994). Axonogenesis, in particular, is well studied in low-density cultures of hippocampal and cerebellar neurons (Dotti et al., 1988; Ferreira et al., 1989; Goslin and Banker, 1989; Diaz et al., 1992). Soon after attachment to the substrate, the cell forms a circumferential lamellipodium (stage 1). In the next 4-8 $\mathrm{hr}$, the lamellipodium coalesces into several short microtubulecontaining neurites or minor processes (stage 2). These processes have the potential to differentiate into either axons or dendrites. After a variable delay of 12-24 hr, during which the minor processes extend and retract for short distances, a single minor process begins to grow rapidly and continuously, taking on morphological and molecular characteristics of the axon (stage 3 ). The remaining minor processes grow more slowly and eventually acquire characteristics of mature dendrites.

In preliminary experiments, we compared the distribution of tau protein to that of tubulin by double-labeling early hippocampal cultures (data not shown). Although tubulin and tau are both present in all processes of stage 2 and stage 3 cells, we observed clear differences in their subcellular localization. Tubulin immunoreactivity appeared to be concentrated within microtubule bundles in minor processes and axons, but was devoid from growth cones. Tau immunoreactivity, on the other hand, was present throughout the neuronal cytoplasm and abundant in growth cones of axons and minor processes, the distal regions of which are known to contain few microtubules (Deitch and Banker, 1993). Detergent extraction of cells in a microtubule-stabilizing buffer 


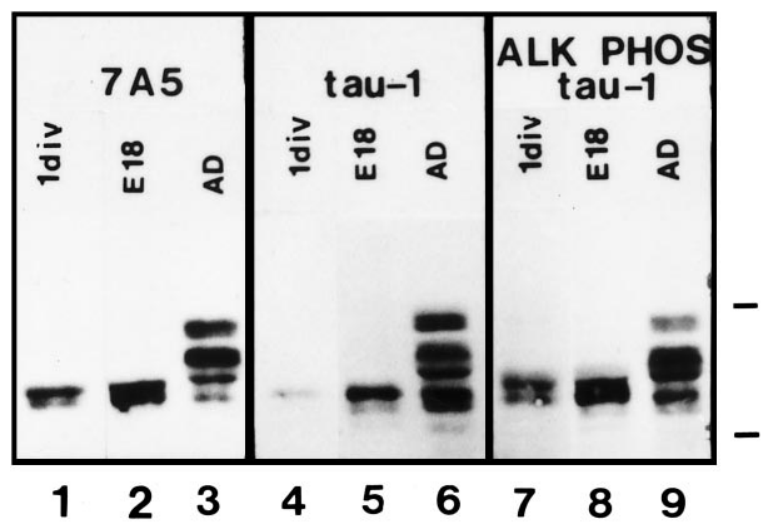

Figure 1. Immunoblot analysis of tau protein in hippocampal cultures. Antibody 7A5 (phosphorylation-independent) reveals two closely spaced bands in $1 \mathrm{~d}$ cultures and E18 hippocampus (lanes 1,2). For reference, an adult rat hippocampal protein sample was run in parallel, showing the higher $M_{\mathrm{r}}$ alternatively spliced isoforms (lane 3 ). Tau-1 recognizes primarily a single band in $1 \mathrm{~d}$ cultures and E18 hippocampus that comigrates with the lower of the total tau bands (lanes 4, 5). After alkaline phosphatase treatment of the blot, tau-1 recognizes the upper band as well, consistent with the unmasking of phosphorylated tau- 1 sites in the upper band (lanes 7, 8). Molecular weight markers: 66 and $45 \mathrm{kDa}$.

rendered the immunostaining patterns for the two proteins identical, consistent with their coexistence in microtubule bundles.

To assess the phosphorylation state of tau during axonogenesis, we carefully compared immunostaining patterns for antibodies tau-1 (dephosphorylation-dependent) and 7A5 (phosphorylationindependent) via double-label immunofluorescence. In stage 2 cells, 7A5 immunoreactivity was found in all cytoplasmic compartments, including the soma, all minor processes, and their growth cones (Fig. 2A). The pattern of tau-1 immunolabeling mirrored that of 7A 5 but was present at uniformly low levels in all compartments (Fig. $2 B$ ). In stage 3 cells, 7A5 labeled the entire axon and its growth cone, as well as the minor processes and their growth cones (Fig. $2 C$ ). In contrast to antibody 7A5, tau-1 immunoreactivity was clearly concentrated in the nascent axon (Fig. $2 D)$. Whereas the intensity of tau- 1 immunoreactivity equaled that of 7A 5 in the distal axon and growth cone (long arrow), tau-1 was much diminished relative to 7A5 in the proximal axon, soma, and in all minor processes and their growth cones (short arrows). It should be noted that stage 2 cells were never observed to have increased tau-1 staining within a single minor process, as might be expected if tau dephosphorylation presaged axonal outgrowth.

The preferential labeling of axons with tau- 1 was consistently observed after either formaldehyde or methanol fixation (data not shown). We discovered, however, that the duration of formaldehyde fixation was critical for preservation of the polarized tau-1 immunolabeling. After short fixation (5-10 min), stage 3 cells had relatively bright tau-1 immunostaining in somata and minor processes as well as axons, such that the pattern of immunolabeling was indistinguishable from 7A5 (Fig. 2E,F).

To determine whether spatial phosphorylation differences exist on microtubule-associated tau, we performed double-labeling after detergent extraction in a microtubule-stabilizing buffer. In stage 2 cells, microtubule bundles within minor processes were prominently labeled with antibody 7A5 (Fig. $3 A$ ) but only weakly with tau-1 (Fig. 3B). Distal growth cone accumulations of tau were lost after extraction, consistent with their content of a significant pool of free tau. In stage 3 cells, 7A5 immunolabeling was prominent on axonal microtubules as well as those in minor processes
(Fig. $3 C$ ). In contrast, tau-1 labeling was brightest on distal axonal microtubules and very low in the proximal axon, soma, and minor processes (Fig. 3D). Quantitative ratio measurements demonstrated a proximo-distal gradient with a three- to fourfold decrease in phosphorylation, similar to that measured for total axonal tau (data not shown). Occasionally, cells in culture extend two (and rarely, three) axons. Double-labeling with 7A5 (Fig. 3E) and tau-1 (Fig. 3F) demonstrated that tau in both axons is preferentially dephosphorylated in distal compared with proximal regions (Fig. 3F).

\section{Quantitative analysis of phosphorylation at the tau-1 epitope: a proximo-distal phosphorylation gradient in nascent axons}

The qualitative observations were confirmed and extended by quantitative analysis of tau phosphorylation state using a ratio immunofluorescence measurement method. All data presented were obtained from cells cultured for $1 \mathrm{~d}$ and fixed with formaldehyde without extraction, and thus reflect the phosphorylation state of microtubule-associated plus unassociated tau protein. Immunofluorescence intensities integrated across the axon width and plotted from base to tip generally revealed a proximo-distal increase for both antibody 7A5 (total tau) and tau-1 (dephosphotau; Fig. 4A). This feature is at least partly attributable to a proximo-distal increase in neurite volume, but may also reflect a distal accumulation of tau in nascent axons. Although the integrated intensity profiles are jagged because of variations in thickness along the axon, the positions of the peaks and valleys are identical for both the tau-1 and 7A5 plots, demonstrating the spatial fidelity of the analysis. In the proximal axon, the integrated tau- 1 intensity is less than one-third that of $7 \mathrm{~A} 5$, but rises to nearly equal that in the distal axon. This is seen clearly in the calculated intensity ratio (tau-1/7A5), which rises smoothly as a proximo-distal gradient, with a threefold increase from the axon origin to tip (Fig. $4 B$ ). To determine the generality of this finding, a series of stage 3 cells (those with 3 or more minor processes and a single axon with a growth cone) was selected under phasecontrast optics. All cells with this morphology exhibited preferential distal axonal labeling with tau-1. Ratio plots for nine axons (length range, 96-194 $\mu \mathrm{m}$ ) were obtained from stage 3 cells from two separate culture preparations (Fig. $4 C$ ). The profiles of the ratio plots were remarkably similar in all 9 cells, with some variation in the maximal ratio value. The gradient generally took the form of an asymptotic curve, with the steepest rise usually within the first 50-75 $\mu \mathrm{m}$. Additionally, a small but sharp increase in ratio was usually observed in the distal axon, at the position of the growth cone.

In contrast to axons, integrated tau- 1 and 7A5 intensities measured out the length of minor processes generally showed a proximo-distal decrease (Fig. 4D). The corresponding ratio plot is flat and low in magnitude (Fig. $4 E$ ). Ratio plots of five additional minor processes (length range, $16-33 \mu \mathrm{m}$ ) revealed similar flat profiles (Fig. $4 F$ ). The magnitude of the ratio values measured in minor processes $(0.2-0.4)$ was similar to that measured in proximal axons and somata.

\section{Calibration of ratio measurements by in situ phosphorylation and dephosphorylation}

Further evidence that the differential labeling patterns obtained with 7A5 and tau-1 represent subcellular differences in tau phosphorylation was obtained by pretreating fixed cells with either a phosphatase or a kinase preparation before immunolabeling. Alkaline phosphatase treatment has been used previously to nonse- 

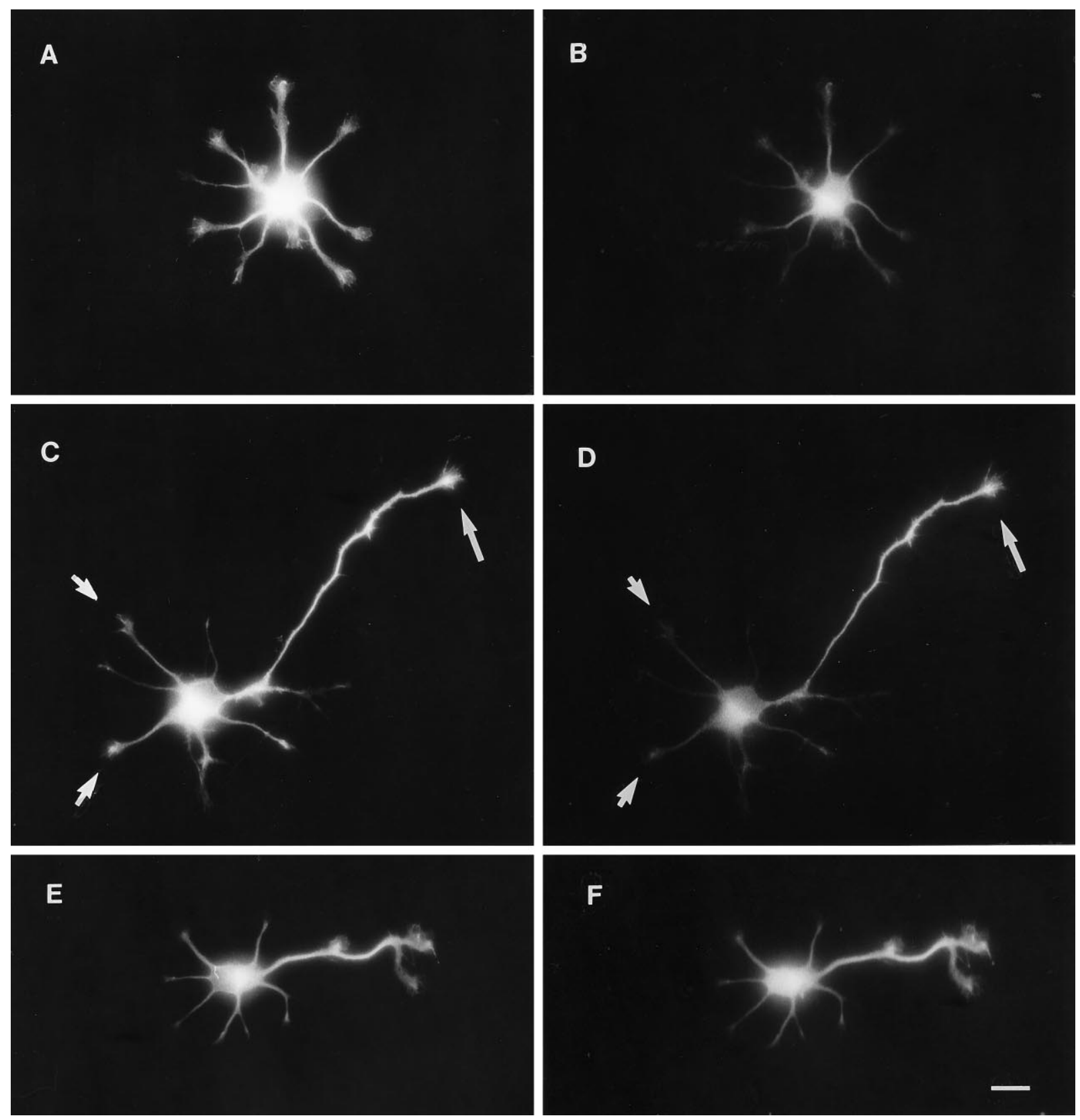

Figure 2. Simultaneous localization of tau protein and a dephosphorylated tau epitope. Neurons cultured for $1 \mathrm{~d}$ were fixed in $4 \%$ formaldehyde for 45 min (except $E$ and $F, 5 \mathrm{~min}$ ) and double-immunolabeled for 7A5 (phosphorylation-independent anti-tau) and tau-1 (dephospho-dependent). $A$, A stage 2 neuron (yet to form an axon) contains 7A5 (total tau) immunoreactivity in the cell body and in all minor processes. $B$, Tau-1 immunostaining, indicating a dephosphorylated tau epitope, is barely detectable in minor processes. Note that there is no apparent concentration of tau-1 immunoreactivity in one of the minor processes, as would be predicted if tau dephosphorylation preceded axonal outgrowth. $C$, In a cell with a newly formed axon, total tau protein is expressed both in minor processes (arrow) and in the axon. $D$, In contrast, tau-1 immunofluorescence is present at high levels in the middle and distal axon but is barely detectable in minor processes and the proximal axon. $E, F$, Short fixation $(5 \mathrm{~min})$ in formaldehyde does not preserve the differential distribution of the tau-1 epitope. A stage 3 neuron contains 7A5 immunoreactivity in soma, minor processes, and axon $(E)$. Tau-1 immunoreactivity appears to mirror total tau distribution in this lightly fixed cell. Scale bar, $10 \mu \mathrm{m}$.

lectively dephosphorylate epitopes in fixed cells, including the one recognized by the tau- 1 antibody (Papasozomenos and Binder, 1987). Phosphorylation of epitopes within fixed cells by kinase activity has not, to our knowledge, been previously reported. We adapted a protocol for in vitro phosphorylation of tau using a crude kinase extract prepared from adult rat brain (Goedert et al., 1993). We first tested the effectiveness of these preparations on partially purified fetal rat tau by SDS-PAGE and immunoblot analysis of mobility shifts (data not shown). Treatment with E. coli alkaline phosphatase for $2 \mathrm{hr}$ at $67^{\circ} \mathrm{C}$ for $2 \mathrm{hr}$ shifted fetal tau migration from a doublet $(\sim 50 \mathrm{kDa})$ to predominantly a single band of higher mobility $(\sim 45 \mathrm{kDa})$, whereas kinase extract treatment for $24 \mathrm{hr}$ at $37^{\circ} \mathrm{C}$ caused a shift to a broad band of lower mobility $(\sim 52-60 \mathrm{kDa})$. Neither treatment gave rise to proteolytic tau fragments, indicating that alterations in immunoreactivity described below were unlikely to be attributable to proteolysis.

Untreated cells, or those incubated in the appropriate buffer without added enzyme, showed the previously described patterns 

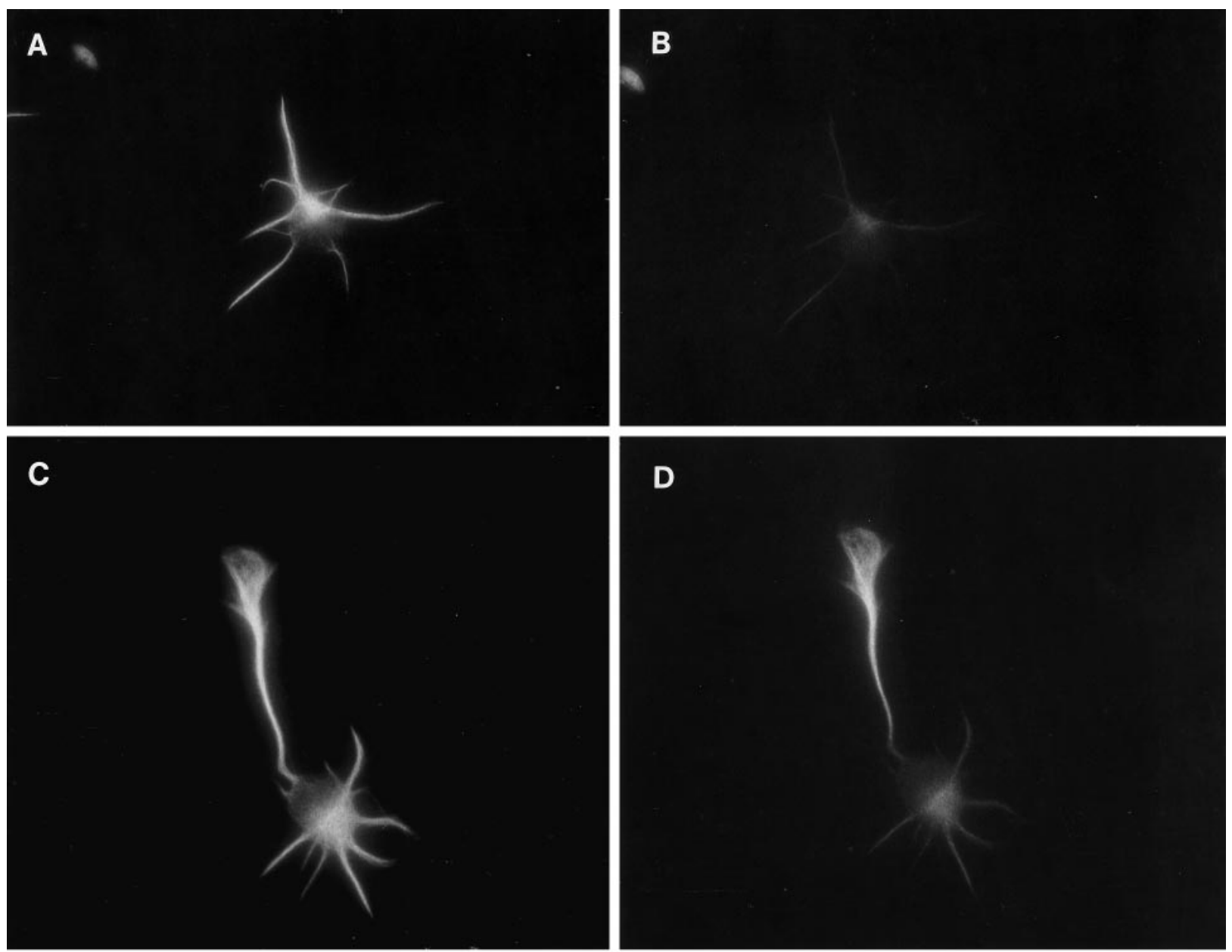

D
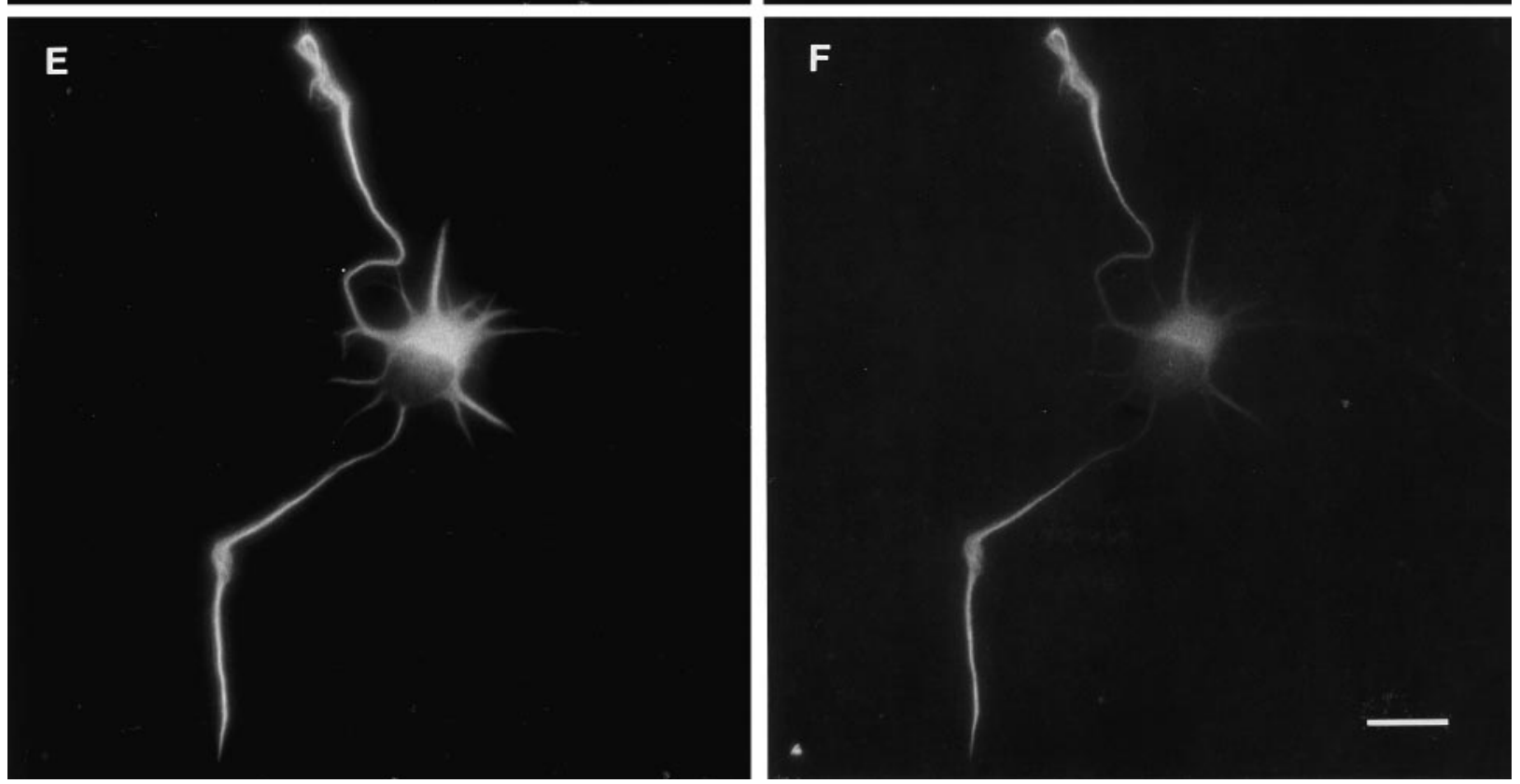

Figure 3. Demonstration of spatial phosphorylation differences in microtubule-associated tau. After extraction with a microtubule-stabilizing buffer and methanol fixation, cells were double-labeled with 7A5 (left) and tau-1 (right). $A$, In a stage 2 cell, tau immunoreactivity (7A5) is present in microtubule bundles in all minor processes. Note that the growth cone accumulations of tau are lost after extraction. $B$, Tau- 1 immunofluorescence is weak but detectable in all of the minor processes of this cell. $C$, In a stage 3 cell, tau protein (7A5) is abundant throughout the axon and in the short, minor processes. $D$, In contrast, tau- 1 immunoreactivity is high within the distal axon but low within proximal axon, soma, and minor processes. $E$, In an unusual stage 3 cell that has formed two axons, tau immunoreactivity (7A5) is present both in axons and in minor processes. $F$, Tau-1 immunoreactivity is concentrated in the distal portions of both axons. Scale bar, $10 \mu \mathrm{m}$. 

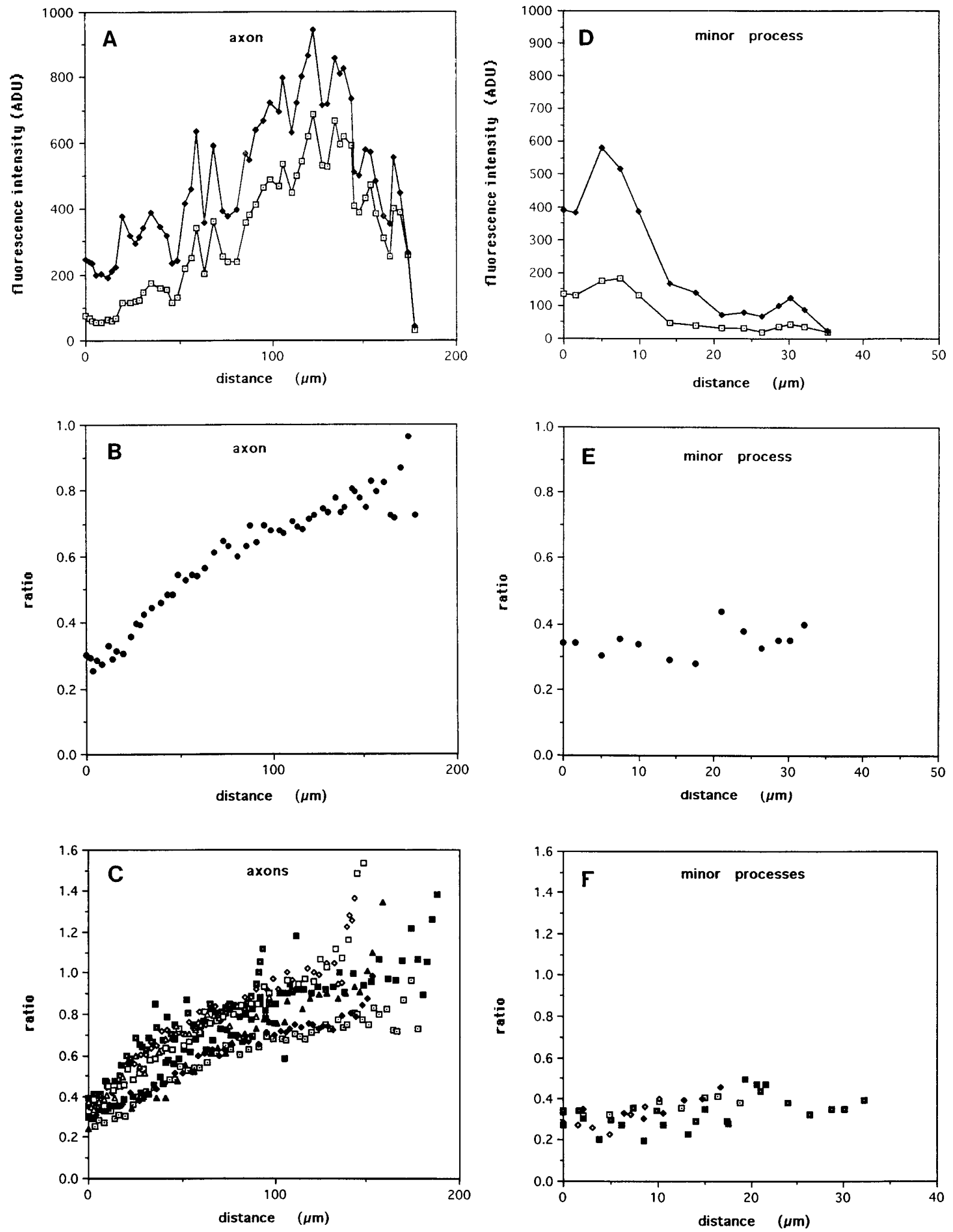

Figure 4. Quantitative analysis of tau phosphorylation by immunofluorescence ratio measurements. $A$, Immunofluorescence intensity measurements were acquired from stage 3 cells. The absolute intensity profiles for both tau- 1 and 7A5 are jagged because of changes in process geometry. However, note that the tau- 1 intensity profile exactly mirrors that of 7A5, but is much lower in the proximal axon and increases relative to 7A5 out the length of the axon. $B$, The ratio of tau-1 to 7A5 intensity, a relative measurement of tau dephosphorylation, is plotted from the axon origin to its tip. The ratio increases smoothly in a proximo-distal manner, with a threefold increase from base to tip. $C$, Axon ratio plots from nine different cells show similar shapes, with the steepest portion of the gradient usually occurring in the first 50-75 $\mu \mathrm{m}$ of axonal length. $D, E$, Intensity and tau-1/7A5 ratio plots are shown for one of the minor process of the same cell. $F$, Ratio values measured in five different minor processes are low, similar to those measured in the proximal axon, and lack a proximo-distal gradient. 
7 A5
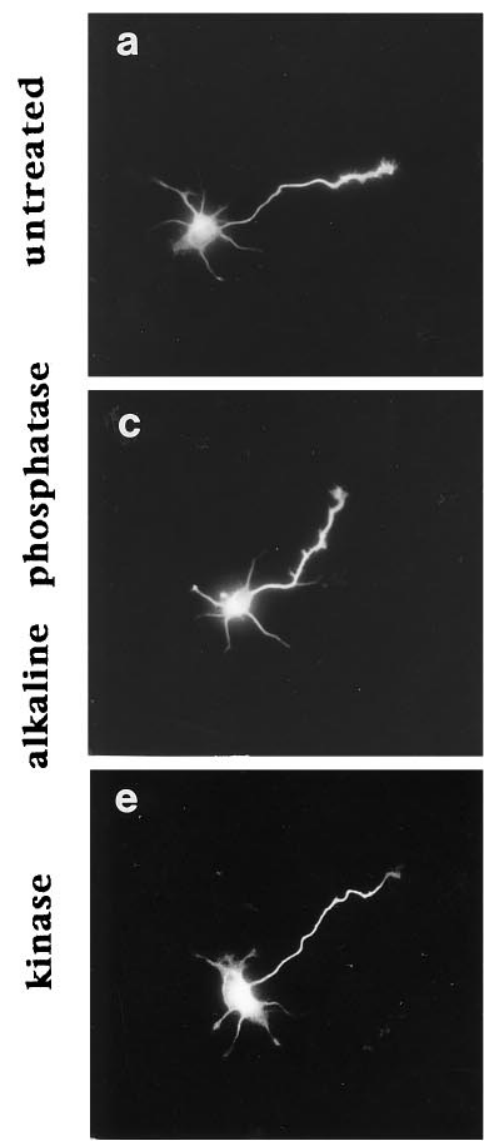

tau -1
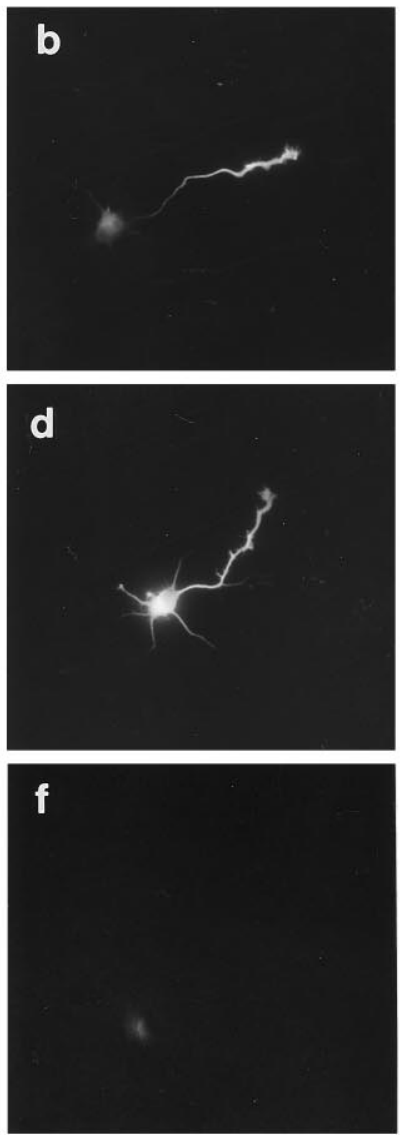

7A5
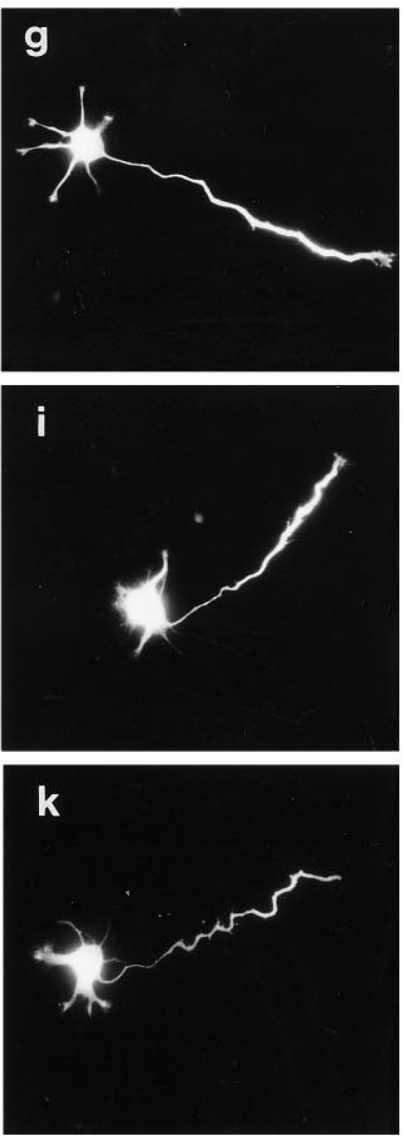

PHF-1
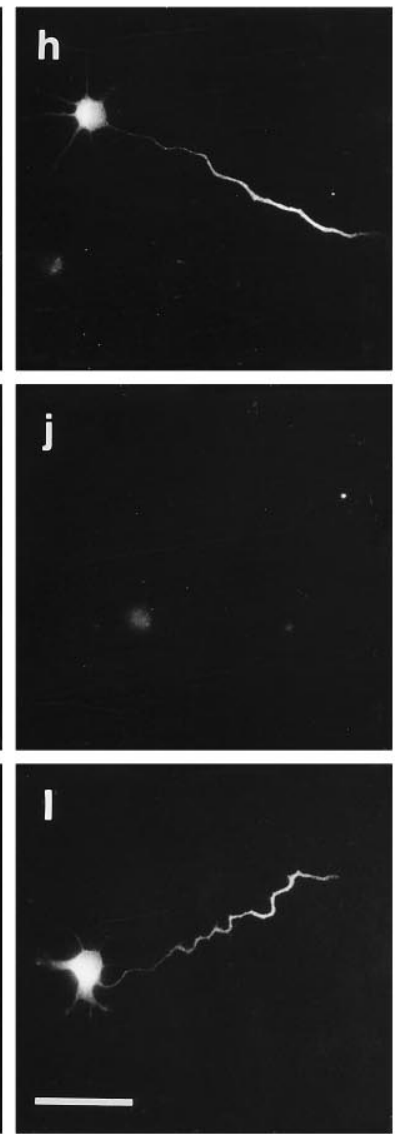

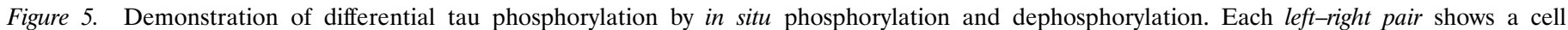

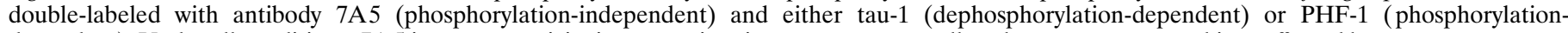

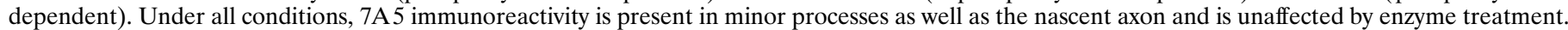

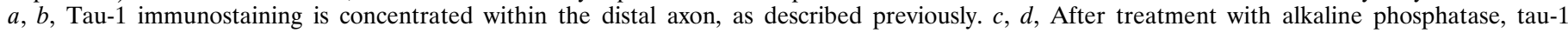

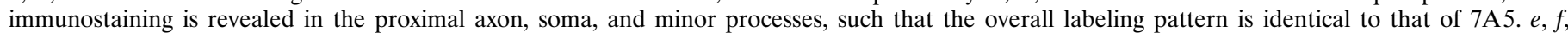

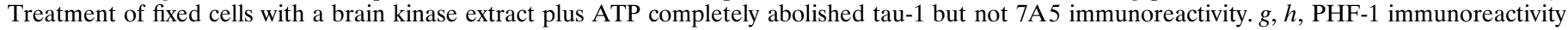

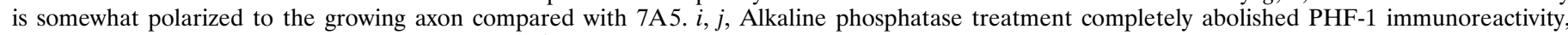

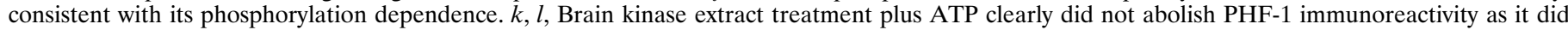

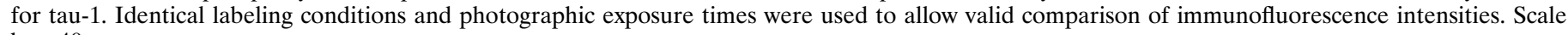
bar, $40 \mu \mathrm{m}$.

of 7A5 and tau-1 immunostaining (Fig. 5a,b). Alkaline phosphatase treatment markedly increased tau- 1 immunoreactivity in proximal axons, somata, and minor processes, such that the staining pattern was identical to that of 7A5, which was unaffected by phosphatase treatment (Fig. $5 c, d$ ). In contrast, kinase extract treatment abolished all tau-1 immunoreactivity without changing 7A5 immunostaining (Fig. 5e,f). The elimination of tau-1 immunoreactivity was dependent on the presence of added ATP. Identical results were obtained with a different monoclonal antibody, BT2, which recognizes an epitope similar or identical to tau-1 (V. Eugeen, Innogenetics, personal communication). PHF-1, a monoclonal antibody raised against Alzheimer's disease paired helical filaments, specifically recognizes a phosphorylated tau epitope at Ser ${ }^{396}$, distinct from the tau-1 site (Greenberg et al., 1992). Double-labeling for 7A5 and PHF-1 revealed in some cells the presence of a proximo-distal increase in PHF-1 immunoreactivity relative to $7 \mathrm{~A} 5$ (Fig. $5 g, h$ ). The apparent magnitude of the differential labeling and its cell-to-cell consistency were, however, less robust than that observed with tau-1. In any case, the PHF-1 labeling (which is dependent on phosphorylation) should change with phosphatase or kinase treatment in a manner opposite to that of tau-1 labeling (which is dependent on dephosphorylation). Indeed, alkaline phosphatase treatment abolished labeling, whereas kinase treatment had no effect or slightly augmented PHF-1 labeling (Fig. $5 i-l$ ).

We performed quantitative ratio analysis on the enzymatically phosphorylated and dephosphorylated cells to obtain "standards" by which to calibrate the arbitrary ratio values to actual percent tau phosphorylation. Tau-1/7A5 ratio plots for two representative untreated axons show a proximo-distal gradient, with a threefold increase from origin to tip (Fig. 6A). Alkaline phosphatase treatment completely abolished the axonal gradient, as seen in the flat ratio plot, and increased the ratio value, consistent with the unmasking of tau-1 sites that were phosphorylated previously. Average ratio profiles from 4-7 cells $( \pm S D)$ were obtained for untreated, alkaline phosphatase-, or kinase-treated axons by sampling ratios within proximal, middle, or distal portions of axons (Fig. 6B). Kinase extract treatment decreased average ratio values 
A

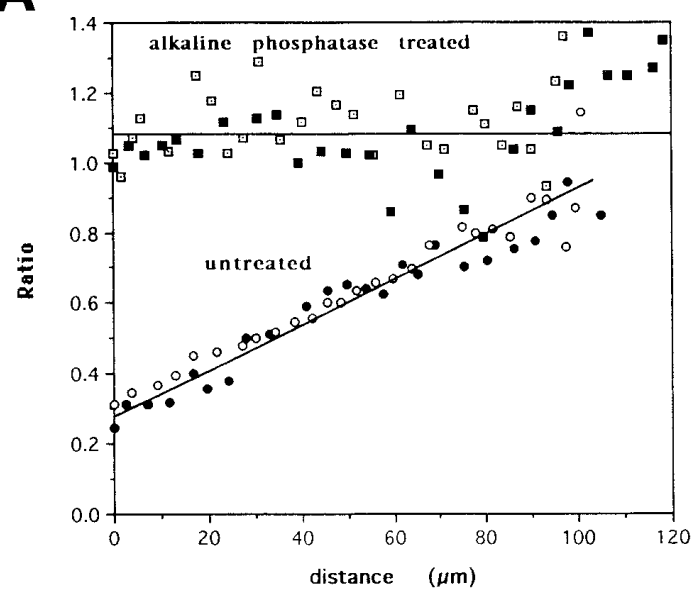

B
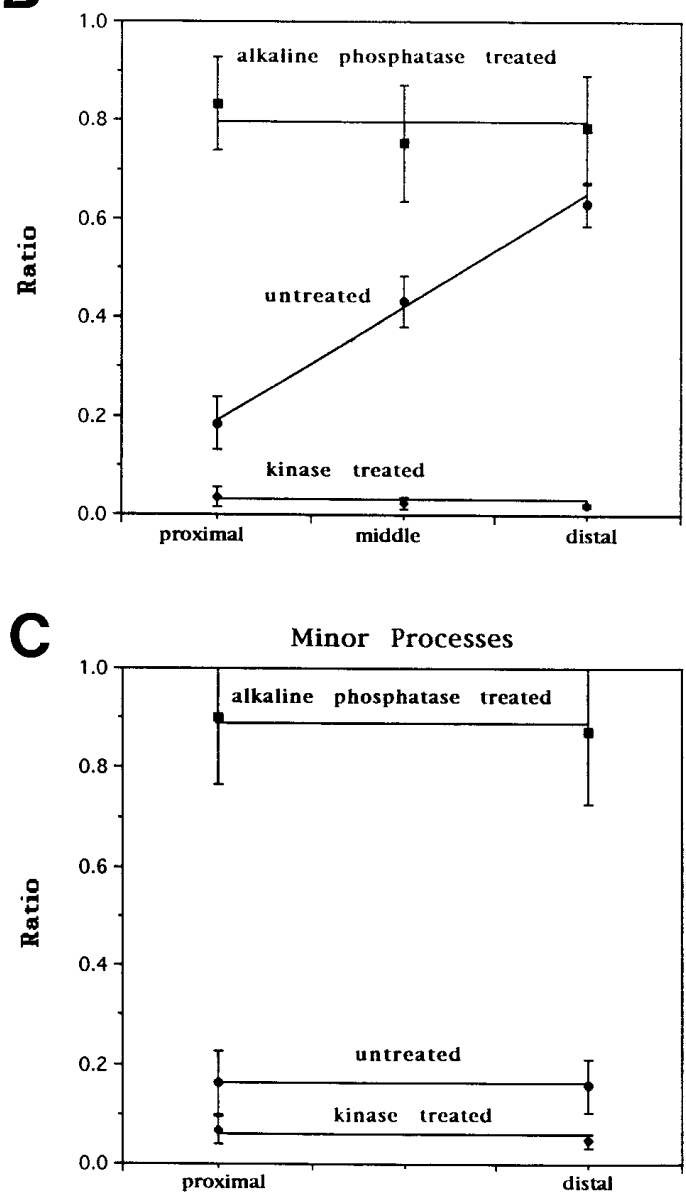

Figure 6. In situ enzymatic dephosphorylation/phosphorylation of tau: quantitative analysis and calibration of tau phosphorylation measurements. $A$, Ratio plots from two representative untreated axons show a proximo-distal gradient, with a nearly threefold increase from origin to tip. Alkaline phosphatase treatment abolished the gradient, such that axons show a completely flat profile and an increase in tau-1/7A 5 ratio, consistent with most of the dephosphorylation occurring proximally. $B$, Averaged data from a different experiment from that shown in $A$, representing untreated $(n=7)$, kinase-treated $(n=4)$, and alkaline phosphatasetreated $(n=7)$ axons. Ratio measurements were taken at three points for each axon: proximal (within $10 \mu \mathrm{m}$ of origin), middle, or distal (within 10 $\mu \mathrm{m}$ of growth cone). Error bars represent SDs. Whereas kinase treatment effectively abolished tau-1 immunoreactivity, reducing the tau-1/7A5 ratio to $<0.1$ at all points along the axon, consistent with the masking of the tau-1 epitope by phosphorylation.

Similar analyses on untreated minor processes revealed low ratios in proximal and distal regions, with ratio values similar to those in proximal axons (Fig. 6C). Ratio measurements of cell somata were similar to those in minor processes (data not shown). Alkaline phosphatase treatment increased the tau-1/7A5 ratio about fourfold in both proximal and distal minor processes, and kinase extract treatment decreased the tau-1/7A 5 ratio to $<0.1$. These quantitative data are consistent with the previous qualitative conclusion that tau is highly phosphorylated in minor processes and proximal axons, and becomes more dephosphorylated out the length of the axon.

Calibration of ratio values to actual percent phosphorylation at the tau- 1 epitope was achieved by assuming that the average ratio measured in phosphatase-treated cells represents $0 \%$ phosphorylation, and that in kinase-treated cells represents $100 \%$ phosphorylation. Because complete phosphorylation/dephosphorylation is probably not achieved, the numbers obtained will underestimate the actual phosphorylation differences. With this caveat, we calculate that $80 \%$ of tau- 1 sites are phosphorylated in minor processes and proximal axons, compared to only $20 \%$ in distal axons.

\section{The tau phosphorylation gradient is dynamically regulated in living cells: perturbation by pervanadate}

The axon-specific dephosphorylation of tau might depend on the localization or local activation of a tau phosphatase. As a preliminary test of this possibility, we treated cultures containing stage 3 neurons with the Ser/Thr phosphatase inhibitors okadaic acid and cyclosporin A. Neither short (1-3 hr) nor long (24 hr) treatments of $1 \mathrm{~d}$ cultures with cyclosporin A $(1-10 \mu \mathrm{M})$ had any obvious effect on the pattern of tau-1 immunoreactivity (data not shown). Ferreira et al. (1993) reported that cyclosporin A treatment of cultured cerebellar neurons led to increased tau phosphorylation and masking of the tau- 1 epitope; our failure to observe this effect may be attributable to intrinsic differences between cultured hippocampal and cerebellar neurons. A number of recent studies have demonstrated the ability of the potent Ser/Thr phosphatase inhibitor okadaic acid to rapidly induce tau hyperphosphorylation in cultured neurons (Arias et al., 1993; Harris et al., 1993). We found, however, that this drug caused neurite retraction before any change in the tau phosphorylation gradient could be detected via tau-1 immunostaining. Finally, agents known to perturb intracellular calcium levels including calcium ionophore A23187 $(1 \mu \mathrm{M}$ for $15 \mathrm{~min})$, caffeine ( $2.5 \mathrm{~mm}$ for $15 \mathrm{~min})$, or elevated external calcium ( $20 \mathrm{mM} \mathrm{CaCl}_{2}$ for $\left.15 \mathrm{~min}\right)$ had no obvious effect on the tau phosphorylation gradient. The latter treatment did induce, however, a pronounced spreading of growth cones.

A group of proline-directed protein kinases recently has been

to $<0.1$, phosphatase treatment significantly increased the ratio in proximal and middle positions and abolished the gradient. $C$, Measurement of tau phosphorylation in minor processes. Compared with untreated minor processes $(n=14)$, alkaline phosphatase treatment increases the tau- 1 / 7A5 ratio three- to fourfold in minor processes both proximally and distally $(n=27)$. Kinase treatment decreases the tau-1/7A 5 ratio in minor processes to $<0.1$ ( $n=10$; error bars represent SDs). All differences between pairs of means of untreated, phosphatase, and kinase ratios are significant by Student's $t$ test $(p<0.01)$. By these measurements, tau is estimated to be $80 \%$ phosphorylated at the tau- 1 epitope in minor processes and proximal axons, and only $20 \%$ phosphorylated in distal axons. 
implicated in phosphorylating tau on Ser-Pro and Thr-Pro sites, including the tau-1 epitope (Drewes et al., 1992; Hanger et al., 1992; Ledesma et al., 1992; Vulliet et al., 1992; Baumann et al., 1993; Lu et al., 1993). These kinases, including MAP kinase, glycogen synthase kinase-3, and cdk5, are themselves tightly regulated by tyrosine phosphorylation (Anderson et al., 1990; Boulton and Cobb, 1991). As a means to modulate the activity of these kinases and thus indirectly perturb tau phosphorylation, we treated cells with pervanadate, the membrane-permeant form of the tyrosine phosphatase inhibitor orthovanadate (Fantus et al., 1989). Pervanadate has been shown to potently inhibit intracellular tyrosine phosphatase activity in a variety of cell types (Heffetz et al., 1990; Volberg et al., 1991; Jalink and Moolenaar, 1992). Pervanadate was prepared by treatment of sodium orthovanadate (1 mM) with hydrogen peroxide (3 mM) in HBSS for $15 \mathrm{~min}$ before addition to $1 \mathrm{~d}$ cultured neurons. Cells fixed after a $15 \mathrm{~min}$ treatment consistently showed a large increase in tau-1 immunoreactivity in somata, minor processes, and proximal axons compared to control neurons (Fig. $7 B, D$ ). Treatment of cells with up to $1 \mathrm{~mm}$ sodium orthovanadate alone for $15 \mathrm{~min}$ had no effect on protein tyrosine phosphorylation or tau phosphorylation (data not shown). The increase in tau- 1 immunoreactivity was seen as early as $5 \mathrm{~min}$ in some experiments. The alteration in tau- 1 immunoreactivity was not observed in control cells treated with buffer alone or with $1 \mathrm{~mm}$ sodium orthovanadate for $15 \mathrm{~min}$. 7A5 immunoreactivity was not altered by pervanadate, indicating that the change in tau- 1 immunoreactivity was not attributable to a redistribution of tau protein, but attributable to a change in phosphorylation state (Fig. $7 A, C$ ). Longer treatment of cells with pervanadate led to beading of cell processes followed by complete retraction within several hours and eventual cell death. Thus, this agent could not be used as a valid test of the role of tau phosphorylation in axonogenesis, which requires $12-24 \mathrm{hr}$ in culture. Long-term ( $24 \mathrm{hr}$ ) treatment of newly plated neurons with $100 \mu \mathrm{M}$ orthovanadate, however, led to hyperphosphorylation on tyrosine of a more limited array of proteins and reversibly inhibited axonal outgrowth (J. Mandell and G. Banker, manuscript in preparation).

To confirm that pervanadate effectively inhibited tyrosine phosphatase activity, we performed anti-phosphotyrosine immunocytochemistry and immunoblotting on $1 \mathrm{~d}$ cultures (Fig. 8). Levels of cellular protein phosphotyrosine immunoreactivity in untreated cells were low but detectable, with focal concentrations present in some growth cones (data not shown). Pervanadate-treated cells showed bright phosphotyrosine immunoreactivity in all cell compartments. Immunoblot analysis revealed a massive pervanadateinduced increase in labeling of many protein bands (Fig. 8, 4G10). Concomitant with this general increase in protein tyrosine phosphorylation, tau became dephosphorylated on at least two distinct serine phosphorylation sites, as demonstrated by immunoblotting. The phosphorylation-independent antibody (7A5) revealed an increased electrophoretic mobility of total tau protein, consistent with dephosphorylation (Fig. 8, 7A5). The pervanadate-induced mobility shift was less marked than that observed after in vitro alkaline phosphatase treatment of fetal rat tau (data not shown), indicating that pervanadate did not induce a complete dephosphorylation of tau on all sites. A dephospho-specific tau antibody (tau-1) gave an increased signal after pervanadate treatment, whereas a phospho-specific antibody $(P H F-1)$ showed decreased binding. These results indicate that tau undergoes a net dephosphorylation (on multiple Ser/Thr residues) in conjunction with pervanadate-induced hyperphosphorylation of many proteins on tyrosine residues.

\section{DISCUSSION}

We have used immunofluorescence ratio image analysis of phosphorylation state-dependent and state-independent antibody labeling to provide subcellular resolution of tau protein phosphorylation state within developing hippocampal neurons. Our results indicate that tau protein is present in all neurites in early developmental stages but is more highly dephosphorylated at the tau-1 epitope in nascent axons than in minor processes (dendrite precursors). Moreover, the change in phosphorylation state takes the form of a smooth proximo-distal gradient, with tau more dephosphorylated in the growth cone than at the axon origin. This finding is especially satisfying because molecular diffusion gradients have been hypothesized to play fundamental roles in many theoretical models of biological morphogenesis (Meinhardt, 1994). An approximate calibration of the ratio measurements to percent maximal phosphorylation was accomplished by enzymatically phosphorylating and dephosphorylating fixed cells for use as "standards." Using this method, we estimate that tau protein is $80 \%$ phosphorylated at the tau- 1 epitope within somata, minor processes, and proximal axons, and only $20 \%$ phosphorylated in distal axons and growth cones. To our knowledge, this is the first calibrated semiquantitative measurement of a specific phosphorylation event at the subcellular level. The calibration procedure should be generally useful for subcellular analyses of protein phosphorylation where appropriate antibodies are available. Finally, we demonstrate that the phosphorylation gradient is dynamic and potentially regulatable by upstream signals involving tyrosine phosphorylation.

\section{Potential mechanisms for generation of the phosphorylation gradient}

The simplest explanation for the observed tau phosphorylation gradient is the existence of a parallel axonal concentration gradient of a relevant phosphatase and/or a complementary somatodendritic distribution of a relevant kinase. To date, however, there is no evidence for an axonally polarized phosphatase. Likewise, two of the proline-directed kinases implicated in phosphorylating tau at the tau- 1 site, p42/p44 MAP kinase and cdk5, appear to have unpolarized distributions in stage 3 cultured hippocampal neurons (J. Mandell, unpublished data). Even if the relevant tau kinases and phosphatases are uniformly distributed during neuronal polarization, they could be locally regulated within the nascent axon by polarized second messengers or regulatory proteins. In fact, second messengers necessary for the activation of many kinases and phosphatases, including calcium and cAMP, have been demonstrated to spontaneously form concentration gradients in growing neurites (Kater et al., 1988; Bentley et al., 1991; Bacskai et al., 1993). A recently characterized neuronal protein that stimulates the activity of cdk5 was shown to be concentrated in axons of hippocampal neurons in vivo and in vitro (Shetty et al., 1995). Thus, both diffusible messengers and regulatory proteins, by virtue of their polarization, may contribute to the establishment of phosphorylation gradients.

An alternative mechanism to the local concentration or activation of kinases/phosphatases is a phosphorylation-dependent transport of tau. Phosphorylation and dephosphorylation could differentially affect anterograde or retrograde transport and thus generate a gradient. Our data, however, do not shed light on specific mechanisms by which the gradient might arise. 

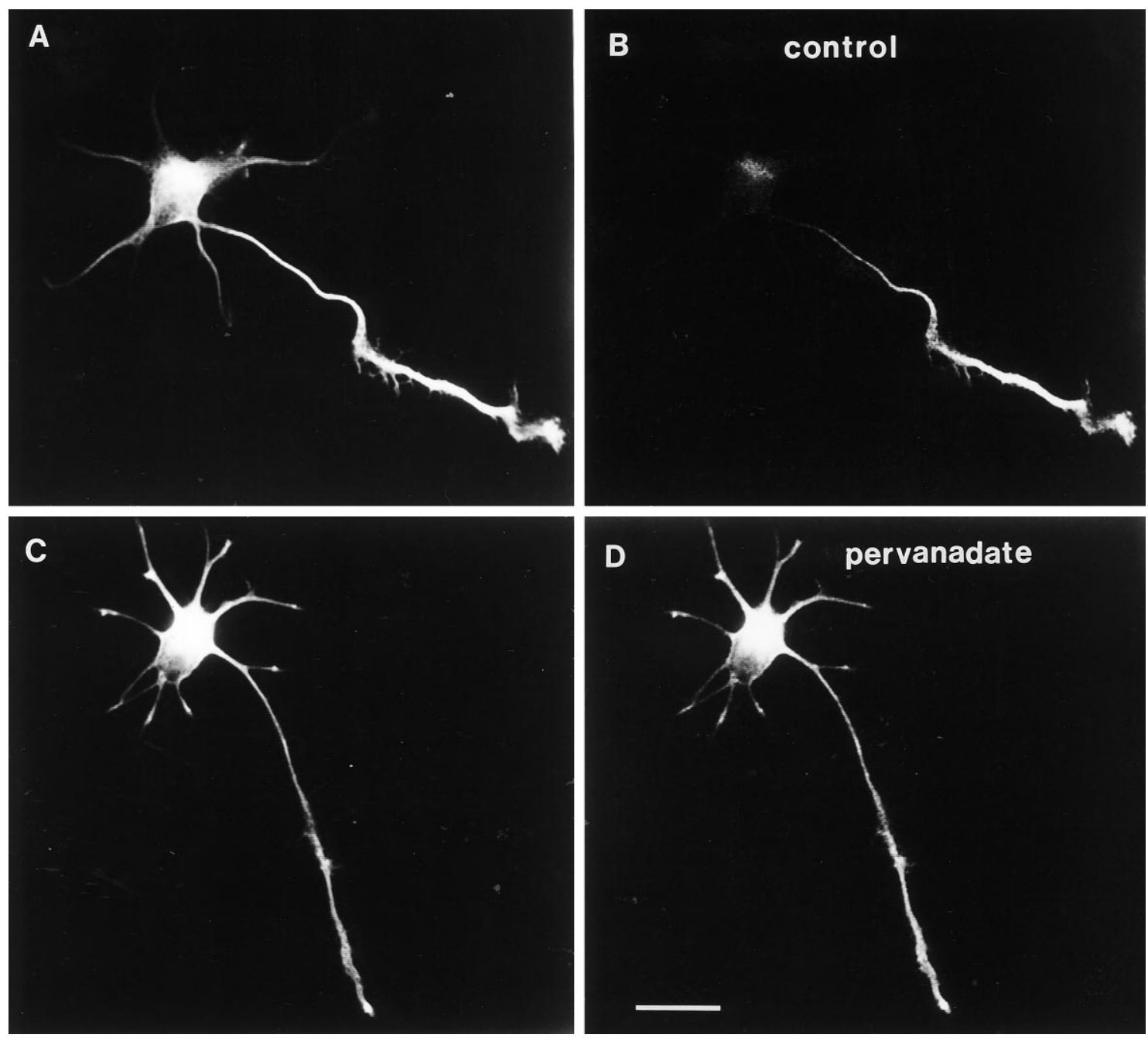

Figure 7. The axonal tau phosphorylation gradient is dynamic: abolishment by pervanadate treatment. Pervanadate treatment does not alter the distribution of total tau protein, as revealed with antibody 7A5 (left panels). In both a control $(A)$ and a pervanadate-treated neuron $(C)$, 7A5 immunolabeling is present in both the minor processes and a newly formed axon. In contrast, tau-1 immunoreactivity is profoundly affected by pervanadate treatment. $B$, A control cell shows the usual pattern of tau-1 immunoreactivity: a proximo-distal axonal gradient and relative absence from minor processes. $D$, Treatment of cultured neurons with $1 \mathrm{~mm}$ pervanadate for 15 min induces the appearance of intense tau- 1 immunoreactivity in the proximal axon and in minor processes, effectively abolishing the phosphorylation gradient. Image acquisition parameters and photographic printing were identical so as to make relative comparisons of intensity meaningful. Scale bar, $20 \mu \mathrm{m}$.

\section{Local modulation of the axonal cytoskeleton by phosphorylation}

Growing evidence indicates that the phosphorylation of MAPs and other cytoskeletal proteins may be locally regulated within developing and mature axons. In agreement with our results, tau was shown to be preferentially dephosphorylated at the tau- 1 site within some developing axons in vivo (Riederer and Binder, 1994). PHF-1 immunolabeling of developing cultured retinal ganglion cells also suggested preferential phosphorylation within the distal growing axon (Pope et al., 1993). However, this study did not control for neuritic volume changes by referencing the phosphorylation-dependent antibody labeling to total tau immunoreactivity. MAP1B has been reported to be selectively phosphorylated within distal portions of growing axons, with an apparent proximo-distal increase in phosphorylation at most of the sites thus examined (Sato-Yoshitake et al., 1989; Mansfield et al., 1991; Black et al., 1994; Ulloa, 1994). Most interestingly, a MAP1B epitope phosphorylated by casein kinase II demonstrated a proximo-distal decrease in phosphorylation (Ulloa, 1994). Thus, there may exist opposing phosphorylation gradients on distinct sites for both tau and MAP1B within growing axons, suggesting the existence of independent regulation of individual phosphorylation sites on MAPs.

Neurofilament proteins are also preferentially phosphorylated within axons (Sternberger and Sternberger, 1983; Nixon and Sihag, 1991; Benson et al., 1996). Moreover, the phosphorylation of neurofilaments within developing axons in vivo and in vitro may take the form of a proximo-distal gradient (Szaro et al., 1989; Benson et al., 1996). Potential roles for axonal neurofilament phosphorylation include the regulation of neurofilament-microtubule interactions and the determination of axonal caliber at nodes of Ranvier and internodal regions (de Waegh et al., 1992; Miyasaka et al., 1993).

\section{Local control of cytoskeletal protein phosphorylation and the development of neuronal polarity}

Might local control of cytoskeletal protein phosphorylation play a role in early axonal differentiation? As suggested previously (Ko- 


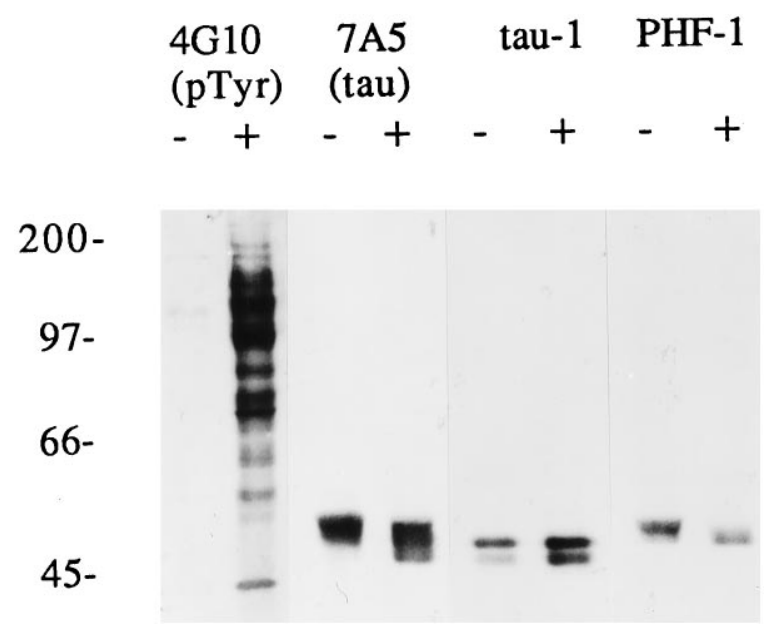

Figure 8. Immunoblot analysis of tau phosphorylation changes induced by pervanadate treatment. Neurons cultured for $1 \mathrm{~d}$ were treated for 15 min with carrier only $(-)$ or with $1 \mathrm{~mm}$ sodium orthovanadate $+3 \mathrm{~mm}$ $\mathrm{H}_{2} \mathrm{O}_{2}(+)$. All lanes represent homogenates from equal numbers of cells. A blot with anti-phosphotyrosine antibody (4G10) demonstrates a massive increase in protein tyrosine phosphorylation after pervanadate treatment. A broad array of bands representing tyrosine phosphorylated proteins is present in pervanadate-treated cells that were absent or barely detectable in control cells. Antibody $7 A 5$ reveals a pervanadate-induced increase in tau electrophoretic mobility, consistent with its dephosphorylation. This is shown for two independent serine-threonine-type sites in the next two panels: tau-1 (dephospho-dependent) immunolabeling is increased, whereas PHF-1 (phospho-dependent) is decreased after pervanadate treatment.

sik and Caceres, 1991), tau dephosphorylation, by enhancing microtubule binding and promoting microtubule assembly and stability, could lead to axonal differentiation and rapid outgrowth. Our immunolocalization data, however, indicate that tau binds to microtubules within minor processes as well as axons, despite the marked difference in phosphorylation at the tau- 1 site. Phosphorylation at this site may have no effect on microtubule binding or, alternatively, it may quantitatively alter binding affinity. In fact, other phosphorylation sites on tau may be more important for the direct regulation of tau-microtubule binding. An elegant molecular dissection based on site-directed mutagenesis has shown that phosphorylation at Ser/Thr-Pro motifs (including the tau-1 site) has little effect on the binding of microtubules compared to phosphorylation at $\mathrm{Ser}^{262}$ (numbered as in the longest human isoform), which greatly decreases the affinity and extent of binding (Biernat et al., 1991). Whether this potentially critical tau modification is locally regulated within developing neurons awaits the production of a site-specific antibody.

Tau may have roles other than the promotion of microtubule stability and assembly. Tau promotes microtubule bundling when overexpressed in several non-neuronal cell types (Kanai et al., 1989; Baas et al., 1991; Knops et al., 1991). This, together with evidence that the shape of the tau molecule is regulated by phosphorylation (Hagestedt et al., 1989), suggests that tau phosphorylation could regulate the bundling and/or spacing of axonal microtubules. Tau may interact with structures other than microtubules. A recent study suggests that tau interacts with a plasma membrane component via its $\mathrm{N}$-terminal domain (Brandt et al., 1995). Membrane-associated tau was found to be concentrated (relative to neurite tubulin levels) in the distal axon and growth cone. Moreover, semiquantitative immunofluorescence analysis revealed the concentration of membrane-associated tau to in- crease as a proximo-distal gradient, with a four- to fivefold increase from soma to growth cone. This change is qualitatively similar to the phosphorylation gradient at the tau-1 site, suggesting the possibility that tau phosphorylation could regulate the linkage of microtubules to a membrane component.

Given the large number of proteins that share phosphorylation consensus sequences, it seems likely that scores if not hundreds of proteins will exhibit spatial gradients of phosphorylation. Cytoskeletal proteins are particularly attractive candidates in which to look for such gradients because they form relatively stable structures on which gradients could form. A recent paper reports the presence of a gradient of myosin II phosphorylation in migrating fibroblasts, such that the level of phosphorylation was lowest at the leading edge (Post et al., 1995). Phosphorylated keratin was shown to assume a polarized distribution in several epithelial cell types (Liao et al., 1995). Whether these play critical roles in morphogenesis or are merely epiphenomena resulting from the promiscuity of many kinases and phosphatases remains to be determined.

The generation and modulation of specific phosphorylation gradients by transmembrane signals could underly the establishment of neuronal polarity. Unlike the situation in culture where the specification of axonal identity is apparently a nondirected, stochastic event, polarization in vivo undoubtedly involves organized extracellular cues present in the neuronal microenvironment. Many of these cues, including extracellular matrix molecules, cell adhesion molecules, neurotransmitters, and diffusible growth factors, act through tyrosine kinase- or phosphatase-linked receptors. For example, activation of the cell adhesion molecule L1 leads to dephosphorylation of tubulin on tyrosine residues (Atashi et al., 1992). Moreover, the L1 molecule itself assumes an axonally polarized distribution in cultured hippocampal neurons, making it an obvious candidate for the local regulation of axonal phosphorylation events (van den Pol and Kim, 1993). Our results with pervanadate suggest that upstream signaling events involving tyrosine phosphorylation may indirectly affect phosphorylation of tau and, presumably, other proteins sharing consensus sites. Whether signaling via a tyrosine kinase- or phosphatase-linked receptor is a primary event in the establishment of neuronal polarity remains to be determined, as does the generality of protein phosphorylation gradients in axonal differentiation and outgrowth.

\section{REFERENCES}

Anderson NG, Maller JL, Tonks NK, Sturgill TW (1990) Requirement for integration of signals from two distinct phosphorylation pathways for activation of MAP kinase. Nature 343:651-653.

Arias C, Sharma N, Davies P, Shafit ZB (1993) Okadaic acid induces early changes in microtubule-associated protein 2 and tau phosphorylation prior to neurodegeneration in cultured cortical neurons. J Neurochem 61:673-682.

Atashi JR, Klinz SG, Ingraham CA, Matten WT, Schachner M, Maness PF (1992) Neural cell adhesion molecules modulate tyrosine phosphorylation of tubulin in nerve growth cone membranes. Neuron 8:831-842.

Baas PW, Pienkowski TP, Kosik KS (1991) Processes induced by tau expression in Sf9 cells have an axon-like microtubule organization. J Cell Biol 115:1333-1344.

Bacskai BJ, Hochner B, Mahaut-Smith M, Adams SR, Kaang B-K, Kandel E, Tsien R (1993) Spatially resolved dynamics of cAMP and protein kinase A subunits in Aplysia sensory neurons. Science 260:222-226.

Baumann K, Mandelkow EM, Biernat J, Piwnica WH, Mandelkow E (1993) Abnormal Alzheimer-like phosphorylation of tau-protein by cyclin-dependent kinases cdk2 and cdk5. FEBS Lett 336:417-424. 
Benson DL, Mandell JW, Shaw G, Banker GA (1996) Compartmentation of alpha-internexin and neurofilament triplet proteins in cultured hippocampal neurons. J Neurocytol 25:181-196.

Bentley D, Guthrie PB, Kater SB (1991) Calcium ion distribution in nascent pioneer axons and coupled preaxonogenesis neurons in situ. J Neurosci 11:1300-1308.

Biernat J, Gustke N, Drewes G, Mandelkow EM, Mandelkow E (1993) Phosphorylation of $\operatorname{Ser}^{262}$ strongly reduces binding of tau to microtubules: distinction between PHF-like immunoreactivity and microtubule binding. Neuron 11:153-163.

Binder LI, Frankfurter A, Rebhun LI (1985) The distribution of tau in the mammalian central nervous system. J Cell Biol 101:1371-1378.

Black MM, Slaughter T, Fischer I (1994) Microtubule-associated protein $1 \mathrm{~b}$ (MAP1b) is concentrated in the distal region of growing axons. J Neurosci 14:857-870.

Boulton TG, Cobb MH (1991) Identification of multiple extracellular signal-regulated kinases (ERKs) with anti-peptide antibodies. Cell Regul 2:357-371.

Brandt R, Leger J, Lee G (1995) Interaction of tau with the neural plasma membrane mediated by tau's amino-terminal projection domain. J Cell Biol 131:1327-1340.

Brion JP, Guilleminot J, Couchie D, Flament DJ, Nunez J (1988) Both adult and juvenile tau microtubule-associated proteins are axon specific in the developing and adult rat cerebellum. Neuroscience 25:139-146.

Brown A, Slaughter T, Black MM (1992) Newly assembled microtubules are concentrated in the proximal and distal regions of growing axons. J Cell Biol 119:867-882.

Brugg B, Matus A (1991) Phosphorylation determines the binding of microtubule-associated protein 2 (MAP2) to microtubules in living cells. J Cell Biol 114:735-743.

Burgoyne RD (1991) High molecular weight microtubule-associated proteins of brain. In: The neuronal cytoskeleton (Burgoyne RD, ed), pp 75-92. New York: Wiley-Liss.

Caceres A, Kosik KS (1990) Inhibition of neurite polarity by tau antisense oligonucleotides in primary cerebellar neurons. Nature 343:461-463.

Caceres A, Banker GA, Binder L (1986) Immunocytochemical localization of tubulin and microtubule-associated protein 2 during the development of hippocampal neurons in culture. J Neurosci 6:714-722.

Caceres A, Potrebic S, Kosik KS (1991) The effect of tau antisense oligonucleotides on neurite formation of cultured cerebellar macroneurons. J Neurosci 11:1515-1523.

Cambray-Deakin MA (1991) Cytoskeleton of the growing axon. In: The neuronal cytoskeleton (Burgoyne RD, ed), pp 233-255. New York: Wiley-Liss.

Chen J, Martin BL, Brautigan DL (1992) Regulation of protein serinethreonine phosphatase type-2A by tyrosine phosphorylation. Science 257:1261-1264.

Craig AM, Banker G (1994) Neuronal polarity. Annu Rev Neurosci 17:267-310

de Waegh S, Lee V, Brady S (1992) Local modulation of neurofilament phosphorylation, axonal caliber, and slow axonal transport by myelinating Schwann cells. Cell 68:451-463.

Deitch JS, Banker GA (1993) An electron microscopic analysis of hippocampal neurons developing in culture: early stages in the emergence of polarity. J Neurosci 13:4301-4315.

Diaz H, Lorenzo A, Carrer HF, Caceres A (1992) Time lapse study of neurite growth in hypothalamic dissociated neurons in culture: sex differences and estrogen effects. J Neurosci Res 33:266-281.

Dotti CG, Banker GA, Binder LI (1987) The expression and distribution of the microtubule-associated proteins tau and microtubule-associated protein 2 in hippocampal neurons in the rat in situ and in cell culture. Neuroscience 23:121-130.

Dotti CG, Sullivan CA, Banker GA (1988) The establishment of polarity by hippocampal neurons in culture. J Neurosci 8:1454-1468.

Drechsel DN, Hyman AA, Cobb MH, Kirschner MW (1992) Modulation of the dynamic instability of tubulin assembly by the microtubuleassociated protein tau. Mol Biol Cell 3:1141-1154.

Drewes G, Lichtenberg KB, Doring F, Mandelkow EM, Biernat J, Goris J, Doree M, Mandelkow E (1992) Mitogen activated protein (MAP) kinase transforms tau protein into an Alzheimer-like state. EMBO J 11:2131-2138.

Fantus IG, Kadota S, Deragon G, Foster B, Posner BI (1989) Pervanadate [peroxide(s) of vanadate] mimics insulin action in rat adipocytes via activation of the insulin receptor tyrosine kinase. Biochemistry 28:8864-8871.

Ferreira A, Busciglio J, Caceres A (1987) An immunocytochemical analysis of the ontogeny of the microtubule-associated proteins MAP-2 and Tau in the nervous system of the rat. Brain Res 431:9-31.

Ferreira A, Busciglio J, Caceres A (1989) Microtubule formation and neurite growth in cerebellar macroneurons which develop in vitro: evidence for the involvement of the microtubule-associated proteins, MAP-1a, HMW-MAP2 and Tau. Brain Res Dev Brain Res 49:215-228.

Garcia DAJ, Correas I, Avila J (1993) Differences in microtubule binding and self-association abilities of bovine brain tau isoforms. $\mathrm{J}$ Biol Chem 268:7976-7982.

Goedert M, Spillantini MG, Jakes R, Rutherford D, Crowther RA (1989) Multiple isoforms of human microtubule-associated protein tau: sequences and localization in neurofibrillary tangles of Alzheimer's disease. Neuron 3:519-526.

Goedert M, Crowther RA, Garner CC (1991) Molecular characterization of microtubule-associated proteins tau and MAP2. Trends Neurosci 14:193-199.

Goedert M, Spillantini MG, Cairns NJ, Crowther RA (1992) Tau proteins of Alzheimer paired helical filaments: abnormal phosphorylation of all six brain isoforms. Neuron 8:159-168.

Goedert M, Jakes R, Crowther RA, Six J, Lubke U, Vandermeeren M, Cras P, Trojanowski JQ, Lee VM (1993) The abnormal phosphorylation of tau protein at Ser-202 in Alzheimer's disease recapitulates phosphorylation during development. Proc Natl Acad Sci USA 90:5066-5070.

Gordon-Weeks PR (1991) Growth cones: the mechanism of neurite advance. Bioessays 13:235-239.

Goslin K, Banker G (1989) Experimental observations on the development of polarity by hippocampal neurons in culture. $\mathrm{J}$ Cell Biol 108:1507-1516.

Goslin K, Banker G (1991) Rat hippocampal neurons in low-density culture. In: Culturing nerve cells (Banker G, ed), pp 25-281. Cambridge: MIT.

Greenberg SG, Davies P, Schein JD, Binder LI (1992) Hydrofluoric acid-treated tau PHF proteins display the same biochemical properties as normal tau. J Biol Chem 267:564-569.

Grundke-Iqbal I, Iqbal K, Tung YC, Quinlan M, Wisniewski HM, Binder LI (1986) Abnormal phosphorylation of the microtubule-associated protein tau (tau) in Alzheimer cytoskeletal pathology. Proc Natl Acad Sci USA 83:4913-4917.

Gustke N, Steiner B, Mandelkow EM, Biernat J, Meyer HE, Goedert M, Mandelkow E (1992) The Alzheimer-like phosphorylation of tau protein reduces microtubule binding and involves Ser-Pro and Thr-Pro motifs. FEBS Lett 307:199-205.

Hagestedt T, Lichtenberg B, Wille H, Mandelkow EM, Mandelkow E (1989) Tau protein becomes long and stiff upon phosphorylation: correlation between paracrystalline structure and degree of phosphorylation. J Cell Biol 109:1643-1651.

Hanger DP, Hughes K, Woodgett JR, Brion JP, Anderton BH (1992) Glycogen synthase kinase-3 induces Alzheimer's disease-like phosphorylation of tau: generation of paired helical filament epitopes and neuronal localisation of the kinase. Neurosci Lett 147:58-62.

Harada A, Oguchi K, Okabe S, Kuno J, Terada S, Ohshima T, SatoYoshitake R, Takei Y, Noda T, Hirokawa N (1994) Altered microtubule organization in small-calibre axons of mice lacking tau protein. Nature 369:488-491.

Harris KA, Oyler GA, Doolittle GM, Vincent I, Lehman RA, Kincaid RL, Billingsley ML (1993) Okadaic acid induces hyperphosphorylated forms of tau protein in human brain slices. Ann Neurol 33:77-87.

Hasegawa M, Morishima KM, Takio K, Suzuki M, Titani K, Ihara Y (1992) Protein sequence and mass spectrometric analyses of tau in the Alzheimer's disease brain. J Biol Chem 267:17047-17054.

Heffetz D, Bushkin I, Dror R, Zick Y (1990) The insulinomimetic agents $\mathrm{H}_{2} \mathrm{O}_{2}$ and vanadate stimulate protein tyrosine phosphorylation in intact cells. J Biol Chem 265:2896-2902.

Himmler A, Drechsel D, Kirschner MW, Martin DWJ (1989) Tau consists of a set of proteins with repeated C-terminal microtubule-binding domains and variable N-terminal domains. Mol Cell Biol 9:1381-1388.

Hirokawa N (1991) Molecular architecture and dynamics of the neuronal cytoskeleton. In: The neuronal cytoskeleton (Burgoyne RD, ed), pp 5-74. New York: Wiley-Liss.

Hirokawa N (1994) Microtubule organization and dynamics dependent on microtubule-associated proteins. Curr Opin Cell Biol 6:74-81. 
Jalink K, Moolenaar WH (1992) Thrombin receptor activation causes rapid neural cell rounding and neurite retraction independent of classic second messengers. J Cell Biol 118:411-419.

Kanai Y, Takemura R, Oshima T, Mori H, Ihara Y, Yanagisawa M, Masaki T, Hirokawa N (1989) Expression of multiple tau isoforms and microtubule bundle formation in fibroblasts transfected with a single tau cDNA. J Cell Biol 109:1173-1184.

Kater SB, Mattson MP, Cohan CC, Connor J (1988) Calcium regulation of the neuronal growth cone. Trends Neurosci 11:315-322.

Knops J, Kosik KS, Lee G, Pardee JD, Cohen GL, McConlogue L (1991) Overexpression of tau in a nonneuronal cell induces long cellular processes. J Cell Biol 114:725-733.

Kosik KS, Caceres A (1991) Tau protein and the establishment of an axonal morphology. J Cell Sci Suppl 15:69-74.

Kosik KS, Finch EA (1987) MAP2 and tau segregate into dendritic and axonal domains after the elaboration of morphologically distinct neurites: an immunocytochemical study of cultured rat cerebrum. J Neurosci 7:3142-3153.

Kosik KS, Orecchio LD, Binder L, Trojanowski JQ, Lee VM, Lee G (1988) Epitopes that span the tau molecule are shared with paired helical filaments. Neuron 1:817-825.

Laemmli UK (1970) Cleavage of structural proteins during the assembly of the head of bacteriophage T4. Nature 227:680-685.

Ledesma MD, Correas I, Avila J, Diaz NJ (1992) Implication of brain cdc2 and MAP2 kinases in the phosphorylation of tau protein in Alzheimer's disease. FEBS Lett 308:218-224.

Lee VM, Balin BJ, Otvos LJ, Trojanowski JQ (1991) A68: a major subunit of paired helical filaments and derivatized forms of normal Tau. Science 251:675-678.

Liao J, Lowthert LA, Ku N-O, Fernandez N, Omary MB (1995) Dynamics of human keratin 18 phosphorylation: polarized distribution of phosphorylated keratins in simple epithelial tissues. J Cell Biol 131:1291-1301.

Lindwall G, Cole RD (1984) Phosphorylation affects the ability of tau protein to promote microtubule assembly. J Biol Chem 259:5301-5305.

Lu Q, Soria JP, Wood JG (1993) p44mpk MAP kinase induces Alzheimer type alterations in tau function and in primary hippocampal neurons. J Neurosci Res 35:439-444.

Mandell JW, Banker GA (1995) The microtubule cytoskeleton and the development of neuronal polarity. Neurobiol Aging 16:229-237.

Mansfield SG, Diaz NJ, Gordon WPR, Avila J (1991) The distribution and phosphorylation of the microtubule-associated protein MAP $1 B$ in growth cones. J Neurocytol 20:1007-1022.

Matus A (1988) Microtubule-associated proteins: their potential role in determining neuronal morphology. Annu Rev Neurosci 11:29-44.

Matus A (1990) Microtubule-associated proteins. Curr Opin Cell Biol 2:10-14.

Matus A (1991) Microtubule-associated proteins and neuronal morphogenesis. J Cell Sci Suppl 15:61-67.

Matus A, Bernhardt R, Hugh JT (1981) High molecular weight microtubule-associated proteins are preferentially associated with dendritic microtubules in brain. Proc Natl Acad Sci USA 78:3010-3014.

Meinhardt H (1994) Biological pattern formation: new observations provide support for theoretical predictions. Bioessays 16:627-632.

Migheli A, Butler M, Brown K, Shelanski ML (1988) Light and electron microscope localization of the microtubule-associated tau protein in rat brain. J Neurosci 8:1846-1851.

Miyasaka H, Okabe S, Ishiguro K, Uchida T, Hirokawa N (1993) Interaction of the tail domain of high molecular weight subunits of neurofilaments with the $\mathrm{COOH}$-terminal region of tubulin and its regulation by tau protein kinase II. J Biol Chem 268:22695-22702.

Nixon RA, Sihag RK (1991) Neurofilament phosphorylation: a new look at regulation and function. Trends Neurosci 14:501-506.

Papasozomenos SC, Binder LI (1987) Phosphorylation determines two distinct species of Tau in the central nervous system. Cell Motil Cytoskeleton 8:210-226.

Peng I, Binder LI, Black MM (1986) Biochemical and immunological analyses of cytoskeletal domains of neurons. J Cell Biol 102:252-262.

Pope W, Enam SA, Bawa N, Miller BE, Ghanbari HA, Klein WL (1993) Phosphorylated tau epitope of Alzheimer's disease is coupled to axon development in the avian central nervous system. Exp Neurol 120:106-113.

Post PL, DeBiasio RL, Taylor DL (1995) A fluorescent protein biosensor of myosin II regulatory light chain phosphorylation reports a gradient of phosphorylated myosin II in migrating cells. Mol Biol Cell 6:1755-1768.

Riederer BM, Binder LI (1994) Differential distribution of tau proteins in developing cat cerebellum. Brain Res Bull 33:155-161.

Sato-Yoshitake R, Shiomura Y, Miyasaka H, Hirokawa N (1989) Microtubule-associated protein 1B: molecular structure, localization, and phosphorylation-dependent expression in developing neurons. Neuron 3:229-238.

Scott CW, Spreen RC, Herman JL, Chow FP, Davison MD, Young J, Caputo CB (1993a) Phosphorylation of recombinant tau by cAMPdependent protein kinase: identification of phosphorylation sites and effect on microtubule assembly. J Biol Chem 268:1166-1173.

Scott CW, Vulliet PR, Caputo CB (1993b) Phosphorylation of tau by proline-directed protein kinase (p34cdc2/p58cyclin A) decreases tauinduced microtubule assembly and antibody SMI33 reactivity. Brain Res 611:237-242.

Shastry BS (1994) More to learn from gene knockouts [review]. Mol Cell Biochem 136:171-182.

Shetty KT, Kaech S, Link WT, Jaffe H, FLores CM, Wray S, Pant HC, Beushausen S (1995) Molecular characterization of a neuronal-specific protein that stimulates the activity of Cdk5. J Neurochem 64: 1988-1995.

Steiner B, Mandelkow EM, Biernat J, Gustke N, Meyer HE, Schmidt B, Mieskes G, Soling HD, Drechsel D, Kirschner MW (1990) Phosphorylation of microtubule-associated protein tau: identification of the site for $\mathrm{Ca}^{2+}$-calmodulin dependent kinase and relationship with tau phosphorylation in Alzheimer tangles. EMBO J 9:3539-3544.

Sternberger N, Sternberger L (1983) Monoclonal antibodies distinguish phosphorylated and nonphosphorylated forms of neurofilaments in situ. Proc Natl Acad Sci USA 80:6126-6130.

Szaro B, Lee V, Gainer H (1989) Spatial and temporal expression of phosphorylated and non-phosphorylated forms of the neurofilament proteins in the developing nervous system of Xenopus laevis. Dev Brain Res 48:87-103.

Szendrei GI, Lee VM, Otvos LJ (1993) Recognition of the minimal epitope of monoclonal antibody Tau-1 depends upon the presence of a phosphate group but not its location. J Neurosci Res 34:243-249.

Towbin H, Staehelin T, Gordon J (1979) Electrophoretic transfer of proteins from polyacrylamide gels to nitrocellulose sheets: procedure and some applications. Proc Natl Acad Sci USA 76:4350-4354.

Trojanowski JQ, Schuck T, Schmidt ML, Lee VM (1989) Distribution of tau proteins in the normal human central and peripheral nervous system. J Histochem Cytochem 37:209-215.

Ulloa L, Diez GF, Avila J, Diaz-Nido J (1994) Localization of differentially phosphorylated isoforms of microtubule-associated protein $1 \mathrm{~B}$ in cultured rat hippocampal neurons. Neuroscience 61:211.

van den Pol A, Kim W (1993) NILE/L1 and NCAM-polysialic acid expression on growing axons of isolated neurons. J Comp Neurol 332:237-257.

Volberg T, Geiger B, Dror R, Zick Y (1991) Modulation of intercellular adherens-type junctions and tyrosine phosphorylation of their components in RSV-transformed cultured chick lens cells. Cell Regul 2:105-120.

Vulliet R, Halloran SM, Braun RK, Smith AJ, Lee G (1992) Prolinedirected phosphorylation of human Tau protein. $\mathbf{J}$ Biol Chem 267:22570-22574

Wood JG, Mirra SS, Pollock NJ, Binder LI (1986) Neurofibrillary tangles of Alzheimer's disease share antigenic determinants with the axonal microtubule-associated protein tau. Proc Natl Acad Sci USA 83: 4040-4043.

Yamamoto H, Saitoh Y, Fukunaga K, Nishimura H, Miyamoto E (1988) Dephosphorylation of microtubule proteins by brain protein phosphatases 1 and $2 \mathrm{~A}$, and its effect on microtubule assembly. J Neurochem 50:1614-1623. 